\title{
Distribution of Dihydropyridine and $\omega$-Conotoxin-sensitive Calcium Currents in Acutely Isolated Rat and Frog Sensory Neuron Somata: Diameter-dependent $L$ Channel Expression in Frog
}

\author{
Reese S. Scroggs and Aaron P. Fox \\ The University of Chicago, Department of Pharmacological and Physiological Sciences, Chicago, Illinois 60637
}

Calcium channel subtypes in adult rat and frog sensory neuron somata, acutely isolated from dorsal root ganglia (DRG neurons), were studied using Bay $K$ 8644, nimodipine, and $\omega$-conotoxin GVIA ( $\omega$-CgTx) as specific probes. The DRG neurons varied in diameter 15-60 $\mu \mathrm{m}$ (rat) and 20-80 $\mu \mathrm{m}$ (frog). Bay K 8644 produced a large increase in calcium currents of small-diameter rat DRG neurons and shifted channel activation and the peak of the I-V curve in the hyperpolarizing direction. At a physiological holding potential (HP) of $-60 \mathrm{mV}$, nimodipine blocked $50 \%$ of the peak calcium current in small-diameter frog and rat DRG neurons, indicating a large $L$ channel component. At HP $-80 \mathrm{mV}$, nimodipine blocked a lower percentage of peak current in small-diameter rat and frog DRG neurons than expected (based on experiments at HP $-60 \mathrm{mV}$ ) probably due to nimodipine's voltage dependence. At HP $-60 \mathrm{mV}, \omega-\mathrm{CgTx}$ blocked $25 \%$ and $50 \%$ of peak current in small-diameter rat and frog DRG neurons, respectively. $\omega$-CgTx blocked a larger percentage of current at HP $-80 \mathrm{mV}$ than at $-60 \mathrm{mV}$, probably because of the repriming of $\mathbf{N}$ channels. Observation of nimodipine- and Bay $K$ 8644-sensitive calcium current in small-diameter rat and frog DRG neurons after $\omega$-CgTx treatment, suggests that $\omega-\mathrm{CgTx}$ is not a potent $L$ channel blocker. The combination of $\omega$ - $\mathrm{CgTx}$ and nimodipine blocked all current in small-diameter frog DRG neurons but left a small portion of current unblocked in small-diameter rat DRG neurons at HP $-60 \mathrm{mV}$, suggesting the possibility of $\omega$-CgTxand nimodipine-insensitive calcium channels in rat DRG neurons. Calcium current in most large-diameter frog DRG neurons was insensitive to nimodipine, but was completely blocked by $\omega$-CgTx. This indicates significant variation in the expression of calcium channel subtypes in small- and largediameter frog DRG neurons, which may subserve different sensory modalities.

Adult rat and frog sensory neuron somata, acutely isolated from dorsal root ganglia (DRG), were studied to determine the contribution to peak calcium current made by pharmacologically unique calcium channel subtypes. The number of unique cal-

Reccived Aug. 7, 1990; revised Nov. 27, 1990; accepted Dec. 4, 1990.

This work was supported by NIH, Klingenstein Fund, McKnight Foundation, Whitaker Foundation, Sloan Foundation, and Sprague Foundation awards to A.P.F., and NIH award to R.S.S.

Correspondence should be addressed to Aaron P. Fox, The University of Chicago, Department of Pharmacological and Physiological Sciences, 947 E. 58th St., Chicago, IL 60637.

Copyright (C) 1991 Society for Neuroscience $0270-6474 / 91 / 111334-13 \$ 03.00 / 0$ cium channels found in neurons and their electrical and pharmacological properties remains somewhat controversial. Originally, three different calcium channels were distinguished in cultured chick sensory neurons on the basis of biophysical and pharmacological properties. The three subtypes were named T-, N-, and L-type calcium channels (Nowycky et al., 1985b). Both $\mathrm{N}$ - and L-type calcium channels required strong depolarizations for activation (high-threshold), but $\mathrm{N}$-type channels needed a much more negative holding potential (HP) to be fully reprimed and inactivated more rapidly during a test pulse than did L-type channels (Nowycky et al., 1985b; Fox et al., 1987a,b). N- and L-type calcium channels also had different unitary slope conductances of $13 \mathrm{pS}$ and $25 \mathrm{pS}$, respectively, although Plummer et al. (1989) have reported that N-type channels also exhibit channel openings with a 22-pS conductance while Kunze and Ritchie (1990) have reported subconductance states for L-type channels with values similar to $\mathrm{N}$-type openings (Kunze and Ritchie, 1990). T-type calcium channels had a unitary conductance of $8 \mathrm{pS}$ and could be activated selectively by weak depolarizations from very negative HPs $(-100 \mathrm{mV}$; Carbone and Lux, 1984a,b; Nowycky et al., 1985b; Fox et al., 1987a,b). Recently, reports of a fourth type of calcium channel, named P-type, have appeared (Llinás et al., 1989). This channel had a unitary conductance similar to N-type but has otherwise not been extensively characterized.

The original description of the L-type calcium channel in heart and skeletal muscle showed that this channel type was extremely sensitive to dihydropyridine (DHP) agonists and antagonists. For the most part, even though DHP-sensitive currents have been shown to exist in neuronal preparations (Nowycky et al., 1985b; Fox et al., 1987a,b), the results have never been as clearcut as those described for muscle (Hess et al., 1984). In fact, several recent reports have suggested that neurons (including sensory neurons), have few or no components of L-type current (Aosaki and Kasai, 1989; Plummer et al., 1989; but see Sah et al., 1989). A second controversy exists as to whether neuronal L-type channels are blocked by the snail toxin $\omega$-conotoxin GVIA $(\omega-\mathrm{CgTx})$. There are reports of potent irreversible block, reversible weak block, or no effect of $\omega$-CgTx on neuronal L channels (Fox et al., 1987a; McCleskey et al., 1987; Holz et al., 1988; Aosaki and Kasai, 1989; Plummer et al., 1989). N-type channels are insensitive to DHP antagonists (Fox et al., 1987b; Hirning et al., 1988; Aosaki and Kasai, 1989) but are sensitive to blockade by $\omega$-CgTx GVIA (McCleskey et al., 1987; Plummer et al., 1989). T-type channels have been demonstrated to be selectively blocked by several agents including $\mathrm{Ni}^{2+}$ and amiloride but only weakly and transiently blocked by $\omega$-CgTx (Nowycky et al., 
1985b; Fox et al., 1987a,b; Kasai et al., 1987; McCleskey et al., 1987; Tang et al., 1988). The P-type calcium channel may be resistant to both DHPs and $\omega$-CgTx (Llinás et al., 1989; Sah et al., 1989). While the physiological roles of these different types of calcium channels are incompletely understood, it seems that $\mathrm{L}$ and $\mathrm{N}$ channels may be involved in neurotransmitter release, while $T$ channels are hypothesized to be involved in regulation of neuronal excitability and pacemaker activity (Llinás and Yarom, 1981; Perney et al., 1986; Hirning et al., 1988; Holz et al., 1988; Tsien et al., 1989).

Previously, cultured DRG neurons prepared from embryonic or neonatal animals have been used for most calcium channel investigations (Carbone and Lux, 1984a,b; Fedulova et al., 1985; Nowycky et al., 1985b; Aosaki and Kasai, 1989). Expression of calcium channcl subtypes in cultured neurons or cell lines can be altered by manipulation of the growth medium (Plummer et al., 1989; Boland and Dingledine, 1990). The acutely isolated DRG neuron somata used in the present study are more likely to retain unique physiological characteristics associated with the transmission of different sensory modalities. Mammalian DRG neuron somata vary greatly in size in a manner that is roughly correlated with their conduction velocity (Yoshida and Matsuda, 1979; Harper and Lawson, 1985a; Lee et al., 1986). In rat DRG neurons, direct measurements of somata size and conduction velocity of attached axons have demonstrated that rapidly conducting $A \alpha$ - and $A \beta$-type DRG neurons have the largest somata, while slower conducting A $\delta$ - and C-type DRG neurons have the smaller somata (Harper and Lawson, 1985a). A $\alpha$ - and A $\beta$-type DRG neurons transmit proprioceptive and tactile information while $\mathrm{A} \delta$ - and C-type DRG neurons transmit pain and thermal information (Martin, 1985). Frog DRG neurons can be differentiated into $\mathrm{C}$ - and A-types, which have conduction velocity ranges very similar to those observed for mammalian DRG neurons (Holz et al., 1986; Morita and Katayama, 1987). Frog C-type DRG somata appear smaller than A-type, based on input resistance measurements (Holz et al., 1985). All experiments on rat DRG neurons outlined in this report were performed on small-diameter somata with average diameters consistent with $\mathrm{C}$ - and A $\delta$-type DRG neurons (Harper and Lawson, 1985a). In most experiments on frog DRG neurons we selected the smallest somata present after isolation for comparison with the above-mentioned rat neurons. However, in one experiment, we studied the calcium channel subtypes in the largest frog DRG somata present after isolation.

In this report, we demonstrate that in small-diameter rat and frog DRG neuron somata, both $\mathrm{L}$ and $\mathrm{N}$ channels contribute significantly to the peak calcium current. At a holding potential of $-60 \mathrm{mV}$, one-half or more of the whole-cell calcium current was L-type in small-diameter frog and rat DRG neuron somata, respectively. These findings put to rest the idea that DHP-sensitive L channels do not contribute significantly to peak calcium current in neurons. Interestingly, this was not the case in largediameter frog DRG neuron somata, which expressed almost exclusively $\mathrm{N}$ channels. These results may indicate that different calcium subtypes are expressed in sensory neurons that transmit different sensory modalities. Further, we show that DHP inhibition of L currents showed a similar requirement for depolarized holding potentials previously described in heart (Bean, 1984; Sanguinetti and Kass, 1984). In rat and frog DRG neuron somata studied, $N$ and $L$ channels could account for almost all of the calcium current at holding potentials between $-60 \mathrm{mV}$ and $-80 \mathrm{mV}$. Although a large amount of $\mathrm{T}$ current $(1 \mathrm{nA})$ could often be demonstrated in rat DRG neuron somata, T current was not prominent unless the holding potential was more negative than $-80 \mathrm{mV}$. Evidence is provided that $\omega-\mathrm{CgTx}$ is not a potent blocker of all L-type calcium channels. Pretreatment of neurons with Bay K 8644 appears either to block or somehow protect calcium channels from $\omega-\mathrm{CgTx}$ block.

\section{Materials and Methods}

Dorsal root ganglia (DRG) were dissected from rats (200-250 g) or frogs (3-4 in) and incubatcd at $35^{\circ} \mathrm{C}$ for $45 \mathrm{~min}$ in Tyrodes solution (140 mM $\mathrm{NaCl}, 4 \mathrm{~mm} \mathrm{KCl}, 2 \mathrm{~mm} \mathrm{MgCl}_{2}, 2 \mathrm{~mm} \mathrm{CaCl}, 10 \mathrm{~mm}$ glucose, $10 \mathrm{~mm}$ HEPES, adjusted to $\mathrm{pH} 7.4$ with $\mathrm{NaOH}$ ) containing $2 \mathrm{mg} / \mathrm{ml}$ collagenase (Sigma Type 1) and $3 \mathrm{mg} / \mathrm{ml}$ dipase (Boehringer-Mannheim), then at $22^{\circ} \mathrm{C}$ for $45 \mathrm{~min}$ in dipase alone. In experiments with large-diameter frog DRG neuron somata, Tyrodes consisted of $100 \mathrm{~mm} \mathrm{NaCl}, 2 \mathrm{~mm}$ $\mathrm{CaCl}_{2}, 2.4 \mathrm{~mm} \mathrm{KCl}, 5.6 \mathrm{~mm}$ glucose, and $20 \mathrm{~mm}$ HEPES, adjusted to pH 7.4 with $\mathrm{NaOH}$, and $5 \mathrm{mg} / \mathrm{ml}$ dipase replaced the usual $3 \mathrm{mg} / \mathrm{ml}$. Single neuronal somata were obtained by tituration in Tyrodes solution through three Pasteur pipettes of progressively smaller bores. Neuronal somata were stored at $5^{\circ} \mathrm{C}$ in Tyrodes and used within $6 \mathrm{hr}$. For experiments, neuronal somata were plated onto a coverslip coated with concanavalin-A and placed in a $1-\mathrm{ml}$ bath for superfusion $(4 \mathrm{ml} / \mathrm{min})$ with control and drug containing solutions. Stock solutions of nimodipine and $( \pm)$ Bay K 8644 (gift from Dr. Scriabinc, Milcs Pharmaceutical, Inc.) were made by dissolving the compounds in 100\% ethanol at concentrations of $10^{-2} \mathrm{M}$. Stock solutions of $(-)$ Bay K 8644 were made in $100 \%$ ethanol at $10^{-2}$ or $10^{-4} \mathrm{M}$. Further dilutions were made in the external buffer used to isolate calcium currents. Nimodipine and $( \pm)$ Bay $\mathrm{K} 8644$ were added to the bath at a concentration of $2 \mu \mathrm{M}$ by superfusion. $(-)$ Bay K 8644 was added directly to the bath by pipette near the cell under study after bath flow was halted, achieving a known final concentration. For experiments involving nimodipine and Bay K 8644, the final concentration of ethanol in the bath was $0.02 \%(4.3 \mathrm{~mm})$. All manipulations involving nimodipine and Bay K 8644 were carried out in the dark to avoid degradation due to photosensitivity. $\omega$-conotoxin GVIA (Peninsula Laboratories) was dissolved in the external buffer used to isolate calcium currents. $\omega$-conotoxin GVIA was added directly to the bath by pipette near the neuron under study after bath flow was halted, achieving a known final concentration.

DRG neuron somata with no processes were voltage clamped by the whole-cell patch technique using an axopatch 1C amplifier (Axon Instruments). The DRG neuron somata varied greatly in diameter. Most of the DRG somata in the study were at the small end of the size spectrum (rat, 19-30 $\mu \mathrm{m}$ in diameter; frog, 20-35 $\mu \mathrm{m}$ in diameter). However, frog neuron somata at the large end of the size spectrum (60$80 \mu \mathrm{m}$ in diameter) were used in one study. Diameter was defined as the average of the distance along the longest and shortest axis of each soma.

Voltage steps, holding potential, and data acquisition and analysis were controlled by an online IBM PC/AT clone computer programmed with the AXOBASIC system (Axon Instruments). Leak sweeps were obtained at several intervals during each experiment by averaging 16 hyperpolarizing test pulses. Leak current was subtracted from the data sweeps by scaling the leak sweep to the data. Usually, several leak sweeps were summed and averaged before subtraction from a data sweep in order to minimize noise introduced by leak subtraction. The patch pipettes were fabricated from soda-lime capillary glass (Scientific Products, B4416-1) using a Narishige 2-stage vertical puller (model PP-83). The electrodes were coated to within $100 \mu \mathrm{m}$ from the tip with sylgard and were heat polished to a resistance of 1.2-1.8 $\mathrm{M} \Omega$ using a Narishige microforge (model MF-83). Gigaohm seals were obtained in Tyrodes solution. We compensated for $80 \%$ of the series resistance by using the Axopatch $1 \mathrm{C}$ series resistance compensation circuit. The data were filtered with an eight-pole Bessel filter at a corner frequency of $3 \mathrm{kHz}$.

To isolate calcium currents in small-diameter frog and rat neuronal somata, the following solutions were employed: the internal solution contained $120 \mathrm{mM} \mathrm{CsCl}_{2}, 5 \mathrm{~mm} \mathrm{Mg-ATP}, 0.4 \mathrm{~mm} 2 \mathrm{Na}-\mathrm{GTP}, 10 \mathrm{~mm}$ EGTA, $20 \mathrm{~mm}$ HEPES, adjusted to $\mathrm{pH} 7.4$ with $\mathrm{CsOH}$ (303 mOsm). The external solution contained $160 \mathrm{~mm}$ TEA-Cl, $10 \mathrm{~mm}$ HEPES, 2 mM $\mathrm{BaCl}_{2}, 100 \mathrm{~nm}$ TTX (rat) or $200 \mathrm{~nm}$ TTX (frog), adjusted to pH 7.4 with TEA-OH (316 mOsm). For isolation of calcium currents in large frog neuron somata, the external solution contained $110 \mathrm{mM}$ TEA$\mathrm{Cl}, 20 \mathrm{~mm}$ HEPES, $2 \mathrm{~mm} \mathrm{BaCl}$, $200 \mathrm{~nm} \mathrm{TTX}$, pH 7.4 (250 mOsm), 


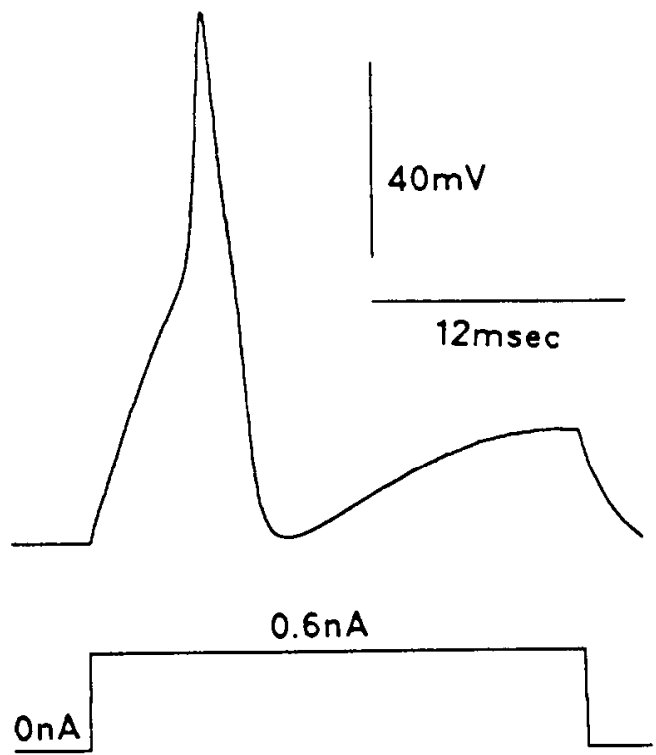

Figure 1. Action potentials could be evoked from an acutely dissociated small-diameter rat DRG neuron. The record was obtained using current clamp mode. $0.6 \mathrm{nA}$ of depolarizing current was injected through the patch electrode. The resting membrane potential was $-64 \mathrm{mV}$. The external solution contained $140 \mathrm{~mm} \mathrm{NaCl}, 4 \mathrm{~mm} \mathrm{KCl}, 2 \mathrm{~mm} \mathrm{MgCl}, 2$ $\mathrm{mM} \mathrm{CaCl}_{2}, 10 \mathrm{~mm}$ glucose, $10 \mathrm{~mm}$ HEPES, $\mathrm{pH}$ 7.4. The internal solution contained $120 \mathrm{~mm} \mathrm{KCl}, 5 \mathrm{~mm} \mathrm{Mg}$-ATP, $0.4 \mathrm{~mm} 2 \mathrm{Na}-\mathrm{GTP}, 10 \mathrm{~mm}$ EGTA, 20 mм HEPES, pH 7.4.

and, in the internal solution, $85 \mathrm{~mm} \mathrm{CsCl}$ replaced the usual $120 \mathrm{~mm}$ concentration ( $240 \mathrm{mOsm}$ ).

The blocking effects of antagonists on current amplitude were determined from plots of peak current versus time. In order to describe the contribution to control peak current made by nimodipine- and $\omega-\mathrm{CgTx}$ sensitive fractions in neurons where both drugs were added sequentially, the effect of each drug was expressed as a percentage of decrease in current amplitude relative to the original control amplitude. For example, if control peak amplitude was $4 \mathrm{nA}$ and addition of drug 1 resulted in blockage of $2 \mathrm{nA}$ and subsequent addition of drug 2 blocked $1.6 \mathrm{nA}$, then this was expressed as "drug 1 blocked $50 \%$ and drug 2 blocked $40 \%$ of the original peak current, leaving $10 \%$ of the original peak current unblocked."

It was necessary to take into account the rate of current rundown, which varied from cell to cell and decreased over time and upon blockade of part of the current. In order to adjust for rundown, a straight line was drawn through the control data points and extrapolated out over the earliest point where the slope of the current versus time relationship in the presence of antagonist matched that observed in the predrug control data. This point was regarded as the control current amplitude. Because some rundown had possibly occurred between the apparent peak effect of one antagonist and the addition of a second antagonist, the data regarding the second antagonist was adjusted by multiplying the percentage of the original current remaining at peak effect of the first antagonist by the percentage change produced by the second antagonist. This adjustment relies on an assumption that different channcl subtypes remaining after treatment with the first antagonist run down at the same rate, and thus the second antagonist would have had the same relative effect if added closer in time to the peak effect of the first antagonist.

\section{Results}

DRG neuron somata observed after isolation in these experiments varied in size about $15-50 \mu \mathrm{m}$ in diameter (rat) or 20$80 \mu \mathrm{m}$ in diameter (frog). Most experiments were restricted to small-diameter somata ranging from $19-30 \mu \mathrm{m}$ in diameter from rat (average $=23.5 \mu \mathrm{m} \pm 3.35 \mathrm{SD}, N=47$ ) and $20-35 \mu \mathrm{m}$ in diameter from frog (average $=28.5 \mu \mathrm{m} \pm 5.09 \mathrm{SD}, N=20$ ).
These DRG neuron somata will be referred to as small-diameter neurons. One set of experiments was performed on large-diameter frog DRG neuron somata ranging $60-80 \mu \mathrm{m}$ in diameter (average $=71.8 \mu \mathrm{m} \pm 6.52 \mathrm{SD}$ ). These will be referred to as large-diameter neurons. As illustrated in Figure 1, acutely isolated small-diameter rat neurons were capable of firing action potentials upon injection of a depolarizing current pulse. For these experiments the external solution was Tyrodes, while the internal solution contained $\mathrm{KCl}$ instead of $\mathrm{CsCl}$ (see Materials and Methods). The average resting potential recorded from 5 such rat neurons was $-55.4 \mathrm{mV} \pm 6.0 \mathrm{SEM}$. These values are similar to those recorded from rat DRG neuron somata in vivo in the presence of a similar extracellular solution (Harper and Lawson, 1985b).

The amplitude of calcium currents recorded from small-diameter rat and frog neurons appeared to be roughly correlated to soma size. Peak currents ranged 2-10 nA in amplitude when evoked from an HP of $-80 \mathrm{mV}$. For these experiments the pipette contained a CsCl-based internal solution while a $2 \mathrm{mM}$ $\mathrm{BaCl}_{2}-160 \mathrm{mM}$ TEA-Cl solution bathed the neurons (see Materials and Methods). Figure $2 A$ plots currents recorded from a small-diameter rat neuron that was held at $-80 \mathrm{mV}$ and stepped to a variety of test potentials. Figure $2 B$ illustrates the peak current versus voltage (I-V) relationship for this neuron. Activation of current in small-diameter rat and frog neurons began at test potentials between $-50 \mathrm{mV}$ and $-40 \mathrm{mV}$, and peak current occurred at test potentials between $-20 \mathrm{mV}$ and -10 $\mathrm{mV}$. The reversal potential measured in small-diameter frog and rat neurons was close to $+50 \mathrm{mV}$.

Changing the holding potential from $-60 \mathrm{mV}$ to $-80 \mathrm{mV}$ increased peak current by an average of $79 \% \pm 18.3$ SEM in six small-diameter rat neurons (Fig. $3 A$ ) and by an average of $70 \%$ in two small-diameter frog neurons tested (not shown). The peak current inactivated more rapidly when evoked from HP $-80 \mathrm{mV}$ versus $-60 \mathrm{mV}$ (Fig. $3 A$ ). At holding potentials negative to $-80 \mathrm{mV}$ substantial $\mathrm{T}$ current could be reprimed. In fact, the $\mathrm{T}$ currents frequently reached amplitudes of $1 \mathrm{nA}$ (Fig. $3 B$ ). Figure $3 B$ illustrates that superfusion with amiloride (200 $\mu \mathrm{M})$ blocked about $45 \%$ of the T current in a small-diameter rat neuron. A small amount of T-type current could usually be evoked in small-diameter rat neurons from $\mathrm{HP}-80 \mathrm{mV}$. In nine small-diameter rat neurons, a depolarizing test pulse to $-50 \mathrm{mV}$ from $\mathrm{HP}-80 \mathrm{mV}$ evoked $\mathrm{T}$ current that averaged $193 \mathrm{pA} \pm 65.4$ SEM.

The DHP calcium channel agonist Bay K 8644, which increases current amplitude through L-type calcium channels by enhancing the probability of channel opening (Hess et al., 1984; Kokubun and Reuter, 1984; Nowycky et al., 1985a), was tested on several small-diameter rat neurons. When racemic $( \pm)$ Bay $\mathrm{K} 8644(2 \mu \mathrm{M})$ was superfused over rat neurons held at -80 $\mathrm{mV}$, calcium channel activation threshold and the peak of the $\mathrm{I}-\mathrm{V}$ curve was shifted in the hyperpolarizing direction (Fig. $4 A$ ). $( \pm)$ Bay K 8644 induced a large increase in current amplitude, which was greatest at weak test depolarizations compared to strong test depolarizations (Fig. $4 A-C$ ). On average $2 \mu \mathrm{M}$ ( \pm )Bay K 8644 increased peak current by $55.5 \% \pm 16.2 \operatorname{SEM}(N=5)$. $( \pm)$ Bay K 8644 also greatly increased the amplitude and decreased the rate of inactivation of the tail current (Fig. 4B,C). The hyperpolarizing shifts of activation and the slowing of tail currents are all characteristics of DHP agonists that have previously been described (Hess et al., 1984; Fox et al., 1987b). Similar results were obtained in six small-diameter rat neurons 

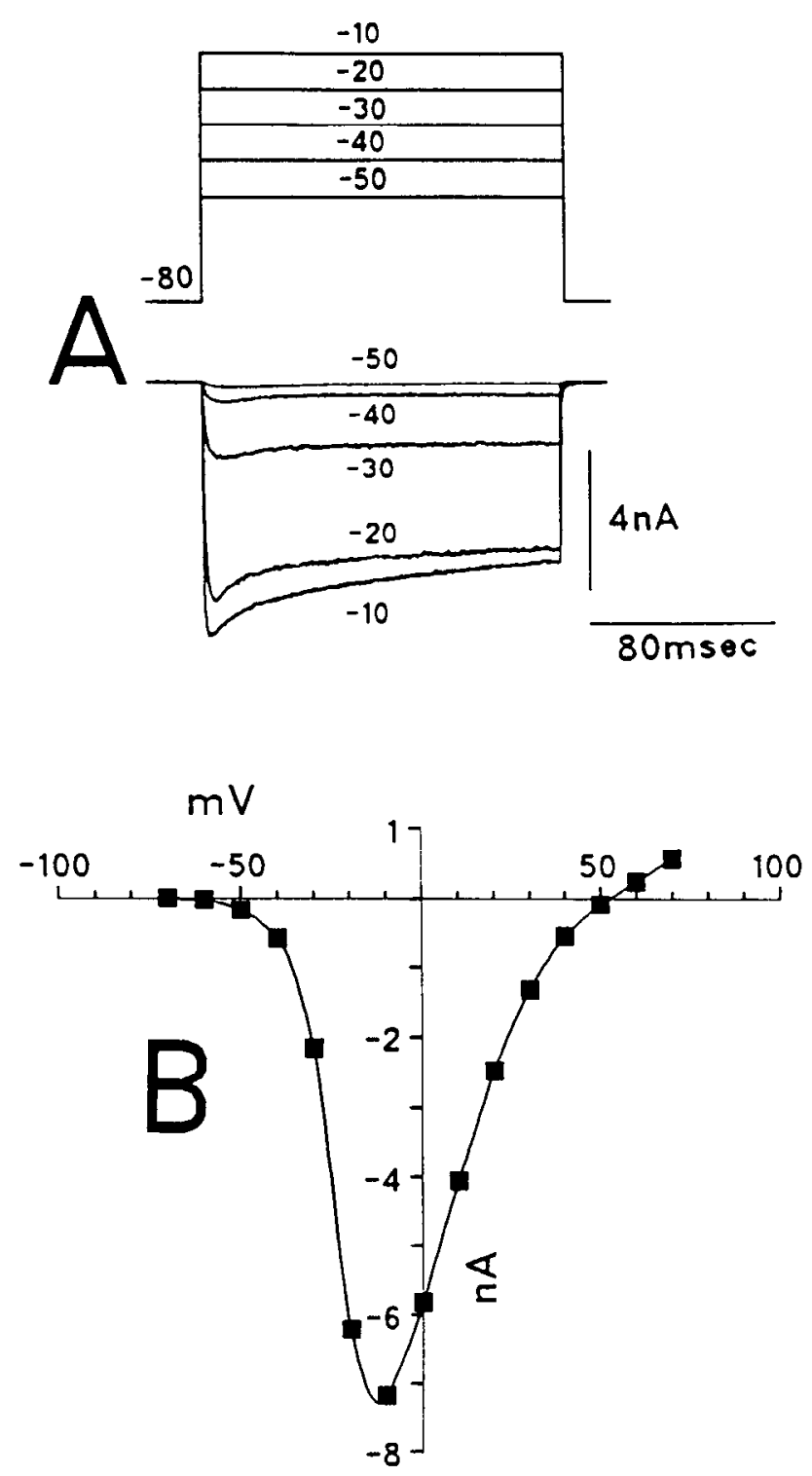

Figure 2. Current as a function of voltage (I-V) relationship in a smalldiameter rat DRG neuron. $A$, Superimposed current records evoked by test depolarizations to a variety of potentials from $\mathrm{HP}-80 \mathrm{mV}$. B, Plot of I-V relationship in the same neuron from $H P-80 \mathrm{mV}$. The external solution contained $160 \mathrm{~mm}$ TEA-Cl, $2 \mathrm{~mm} \mathrm{BaCl}{ }_{2} .100 \mathrm{~nm}$ TTX, $10 \mathrm{~mm}$ HEPES, pH 7.4. The internal solution contained $120 \mathrm{~mm} \mathrm{CsCl}, 5 \mathrm{~mm}$ Mg-ATP, 0.4 mM 2Na-GTP, 10 mM EGTA, 20 mM HEPES, pH 7.4.

with the optically pure agonist (-)Bay K $8644(100-\mu$ l bolus at a concentration of $200 \mu \mathrm{M}$ ), which increased peak current by an average of $26 \% \pm 8.5 \mathrm{SEM}$ when pipetted into the $1-\mathrm{ml}$ bath near the cell under study, achieving a final concentration of $\approx 18$ nM. The increase in calcium current amplitude by Bay K 8644 demonstrates that a significant portion of the calcium current in the small-diameter rat neurons was conducted through L-type channels.

Another group of experiments explored the inhibition of calcium currents produced by the DHP calcium channel antagonist, nimodipine, and the marine snail calcium channel antagonist, $\omega$-CgTx. Nimodipine is believed to inhibit primarily L-type calcium channels (but see Cohen and McCarthy, 1987; Akaike et al., 1989) while $\omega$-CgTx is thought to block N-type and possibly L-type calcium channels (McCleskey et al., 1987;
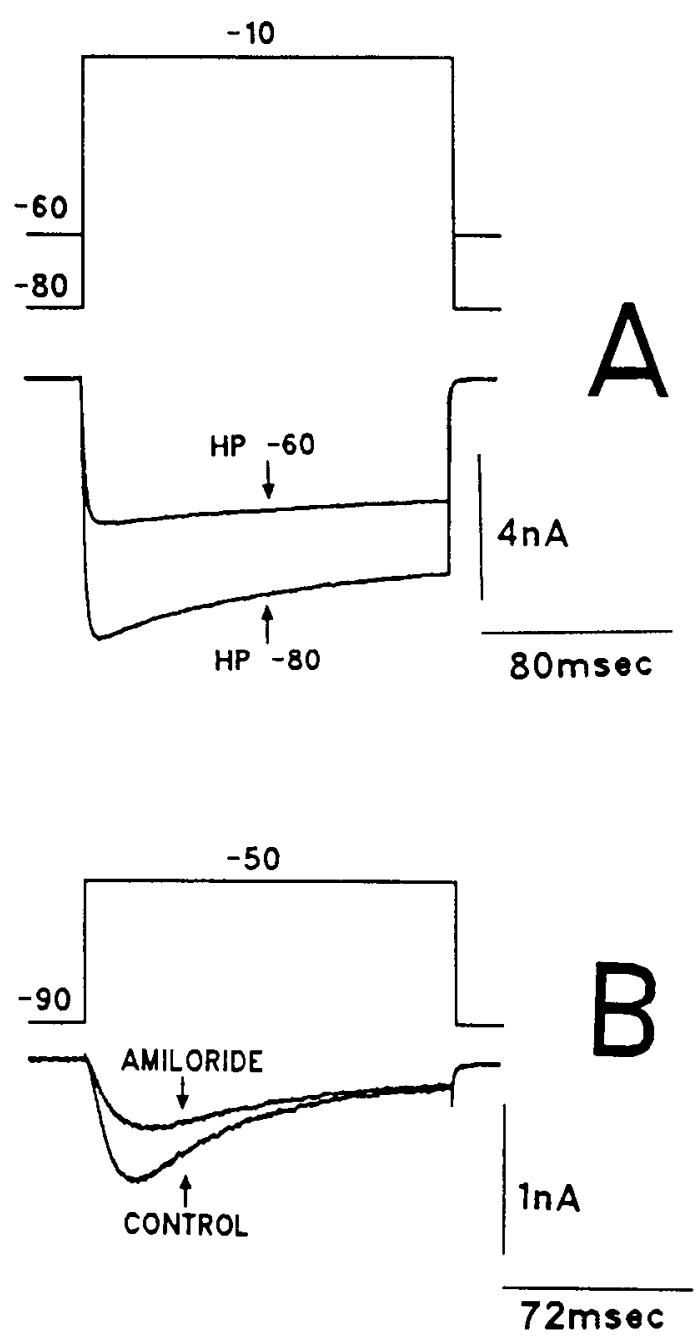

Figure 3. Changing the cell holding potential reprimed a large component of calcium current in small-diameter rat DRG neurons. $A$, Upon changing from $\mathrm{HP}-60 \mathrm{mV}$ to $\mathrm{HP}-80 \mathrm{mV}$, the peak calcium current increased by $77 \%$. $B$, Holding a small-diameter rat cell at $-90 \mathrm{mV}$ and stepping to $-50 \mathrm{mV}$ evoked a low threshold, rapidly inactivating $(\mathrm{T})$ calcium current. $45 \%$ of the $T$ current was blocked by superfusion with $200 \mu \mathrm{M}$ amiloride. Solutions as in Figure 2.

Aosaki and Kasai, 1989; Plummer et al., 1989). The inhibitory action of nimodipine and $\omega$-CgTx on peak calcium current in small-diameter rat and frog neurons was compared at two different HPs, $-60 \mathrm{mV}$ and $-80 \mathrm{mV}$. For these experiments smalldiameter rat and frog neurons were depolarized to a test potential that evoked peak current at a stimulation rate of one depolarization every 10,20 , or $30 \mathrm{sec}$. A constant stimulation rate was used throughout each experiment. After a baseline of 5-10 depolarizations was established, nimodipine $(2 \mu \mathrm{M})$ was superfused over the neurons. Then, after a second baseline was established in the presence of nimodipine, the bath flow was halted and a $100-\mu \mathrm{l}$ bolus of $10 \mu \mathrm{M} \omega-\mathrm{CgTx}$ was pipetted into the 1-ml bath near the neuron under study, achieving a final concentration of $\approx 0.9 \mu \mathrm{M}$. Figure $5 A$ shows a peak current versus time plot obtained from a small-diameter frog neuron held at $-60 \mathrm{mV}$ where nimodipine blocked $40 \%$ of the peak current. Subsequent addition of $\omega$-CgTx blocked all of the current that remained in this neuron. Figure $5 B$ shows a peak current versus time plot obtained from a small-diameter rat neuron held at 

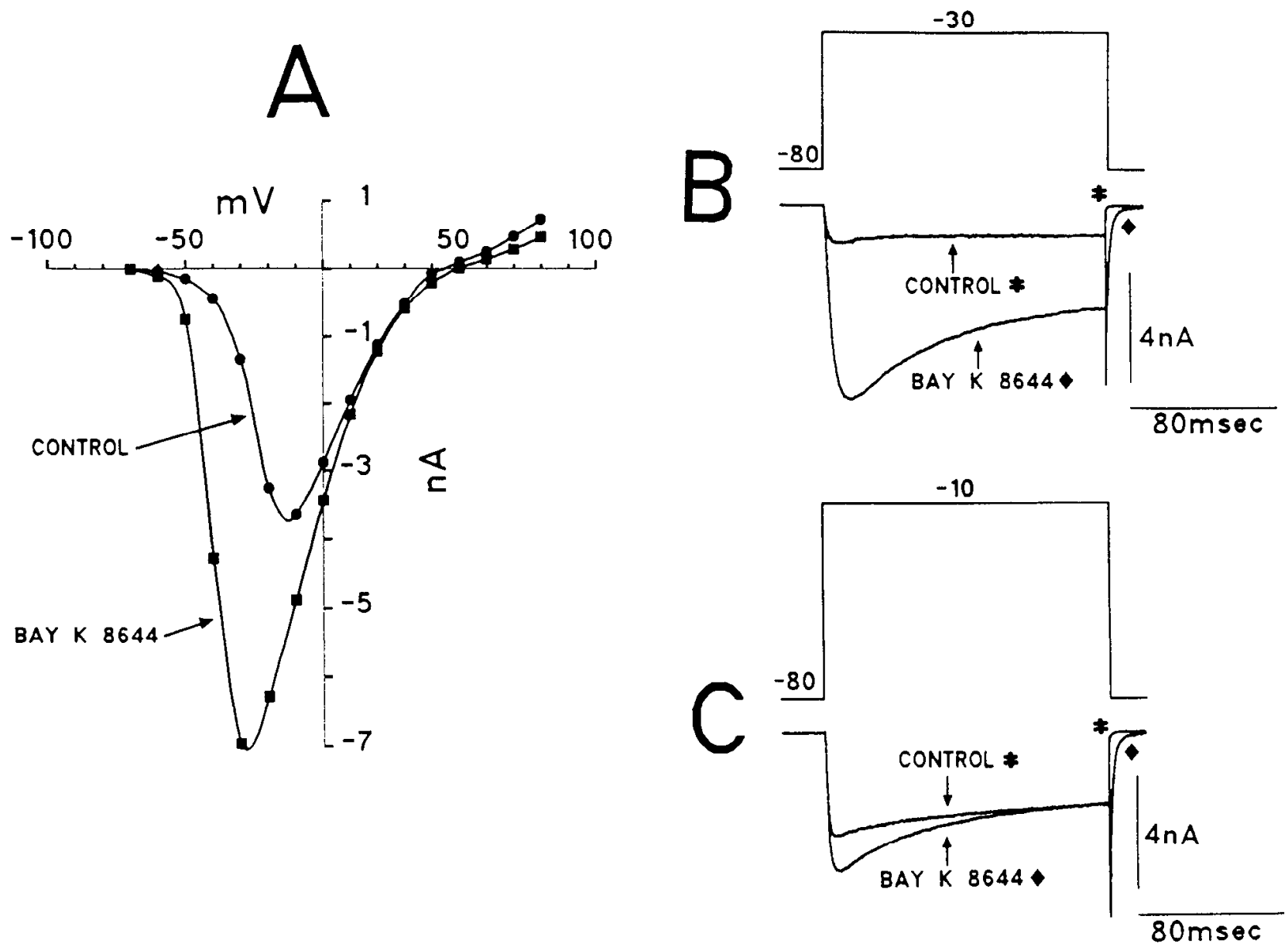

Figure 4. Effect of ( \pm Bay K 8644 on calcium current recorded from a small-diameter rat DRG neuron. $A$, I-V relationships under control conditions $(\ominus)$, and after $2 \mu \mathrm{M}( \pm)$ Bay K 8644 was administered to the bath by superfusion $(\square)$. Treatment with $( \pm)$ Bay $\mathrm{K} 8644$ greatly increased current amplitude. Note that Bay K 8644 shifted activation and the peak of the I-V curve in the hyperpolarizing direction. $B$, $C$, Current traces recorded from the same neuron as $A$. Note the dramatic increase in current amplitude at a weak depolarization to $-30 \mathrm{mV}$ from $\mathrm{HP}-80 \mathrm{mV}$ versus the smaller increase in current amplitude observed during stronger depolarization to $-10 \mathrm{mV}$ from $\mathrm{HP}-80 \mathrm{mV}$. ( \pm )Bay $K 8644(\$)$ increased the amplitude and decreased the rate of inactivation of tail currents compared to controls $\left(^{*}\right)$ in $B$ and $C$. Holding potential was -80 $\mathrm{mV}$ in $A, B$, and $C$. Solutions as in Figure 2.

$-60 \mathrm{mV}$ where application of nimodipine blocked $69 \%$ of the current. Subsequent addition of $\omega$-CgTx blocked an additional $18 \%$ of the original peak current in this neuron. Representative current traces from the different experimental conditions are plotted above the graphs. On average, nimodipine blocked $46 \%$ of the calcium current in small-diameter frog neurons (Table 1) and $58 \%$ of the peak current in small-diameter rat neurons at $\mathrm{HP}-60 \mathrm{mV}$ (Table 1). Subsequent addition of $\omega$-CgTx blocked an average of $52 \%$ of the original peak current (all that remained) in the frog neurons and an average of $27 \%$ of the original peak current in the rat neurons held at $-60 \mathrm{mV}$. These results indicate that a large portion of peak whole-cell current in small-diameter

Table 1. Blockade of calcium current in small-diameter frog and rat DRG neurons at different holding potentials

\begin{tabular}{llllcr} 
Species & $\begin{array}{l}\text { Holding } \\
\text { potential }(\mathrm{mV})\end{array}$ & $\begin{array}{l}\text { \% decrease } \\
\text { nimodipine* }\end{array}$ & $\begin{array}{l}\text { \% decrease } \\
\omega-\text { CgTx }^{*}\end{array}$ & $\begin{array}{l}\text { \% current } \\
\text { remaining* }\end{array}$ & $N$ \\
\hline Frog & -60 & $46 \pm 4.0$ & $52 \pm 4.3$ & $1.6 \pm 0.7$ & 7 \\
Frog & 80 & $12 \pm 3.7$ & $76 \pm 4.6$ & $13 \pm 2.1$ & 6 \\
Rat & -60 & $58 \pm 6.3$ & $27 \pm 4.8$ & $15 \pm 5.8$ & 5 \\
Rat & -80 & $23 \pm 3.8$ & $48 \pm 3.9$ & $29 \pm 2.3$ & 10
\end{tabular}

Smal!-diameter frog and rat DRG neurons were first superfused with $2 \mu \mathrm{M}$ nimodipine. After the peak effect of nimodipine was observed, the bath flow was stopped and a $100-\mu \mathrm{l}$ bolus of $10 \mu \mathrm{M} \omega-\mathrm{CgTx}$ was pipetted into the bath near the neuron, achieving a final concentration of $0.9 \mu \mathrm{M}$.

* Percent decrease \pm SEM produced by each drug. 

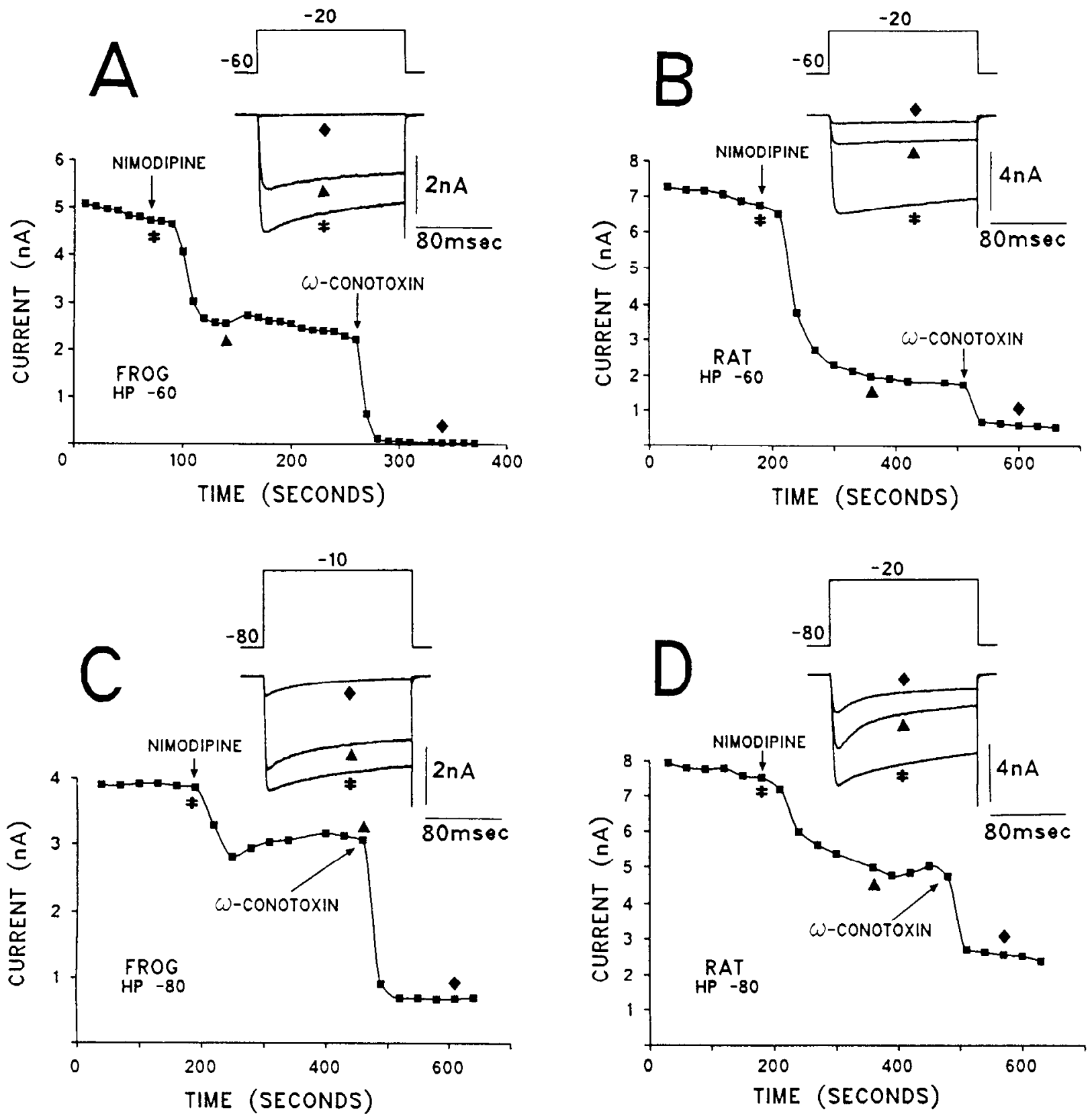

Figure 5. Nimodipine and $\omega$-CgTx blocked a large fraction of calcium current in small-diameter rat and frog DRG neurons held at $-60 \mathrm{mV}$ versus $-80 \mathrm{mV}$. Plot of current versus time in a small-diameter frog $(A)$ and rat $(B)$ DRG neuron held at $-60 \mathrm{mV}$. The neurons were depolarized to $-20 \mathrm{mV}$ every $10 \mathrm{sec}$ (frog) or $30 \mathrm{sec}$ (rat). Superfusion with $2 \mu \mathrm{M}$ nimodipine blocked $41.8 \%$ of peak current in the frog neuron and $68.3 \%$ of peak current in the rat neuron. After bath flow was stopped, 100- $\mu$ l bolus of $10 \mu \mathrm{M} \omega-\mathrm{CgTx}$ was pipetted into the 1-ml bath near each neuron, which blocked all remaining current in the frog neuron $(58.2 \%$ of original peak current) and $20.4 \%$ of the original peak current in the rat neuron, leaving $11.3 \%$ of the original current unblocked. Plot of current versus time in a small-diameter frog $(C)$ and rat $(D)$ DRG neuron held at -80 $\mathrm{mV}$. Cells were depolarized to $-10 \mathrm{mV}$ every $20 \mathrm{sec}$. Superfusion with $2 \mu \mathrm{M}$ nimodipine blocked $20.5 \%$ of the peak current in the frog neuron and $29.4 \%$ of the peak current in the rat neuron. After the bath flow was stopped, a $100-\mu l$ bolus of $10 \mu \mathrm{M} \omega$-CgTx was pipetted into the 1 -ml bath near each neuron which blocked an additional $60.7 \%$ of the original peak current in the frog neuron and an additional $30.1 \%$ of the peak current in the rat neuron. The combination of nimodipine and $\omega$-CgTx left $18.2 \%$ and $40.5 \%$ of the current unblocked in frog and rat, respectively. Insets $(A-D)$ are superimposed current traces illustrating points along each plot of current versus time; control $\left({ }^{*}\right)$, after nimodipine $(\boldsymbol{\Delta})$, and after $\omega$ - $C g T x(\boldsymbol{})$. The symbols over the current versus time plots show where the records were obtained. Note the increase in inactivation observed after superfusion in the presence of nimodipine at $\mathrm{HP}-80 \mathrm{mV}$. Solutions as in Figure 2.

rat and frog neurons held at $-60 \mathrm{mV}$ was conducted through L-type calcium channels. The effect of $\omega$-CgTx can be attributed to the block of $\mathrm{N}$-type calcium channels (Table 1 ).

At $\mathrm{HP}-80 \mathrm{mV}$, the action of nimodipine and $\omega$-CgTx displayed a much different profile. Figure $5 C$ shows that superfusion with nimodipine at $\mathrm{HP}-80 \mathrm{mV}$ blocked $18 \%$ of the current in a small-diameter frog neuron, and subsequent addition of $\omega$-CgTx blocked an additional $64 \%$ of the current. As illustrated in Figure $5 D$, superfusion of a small-diameter rat neuron with nimodipine at $\mathrm{HP}-80 \mathrm{mV}$ blocked $30 \%$ of the peak current, and subsequent addition of $\omega$-CgTx blocked an additional $32 \%$ of the current. The representative current traces plotted above 

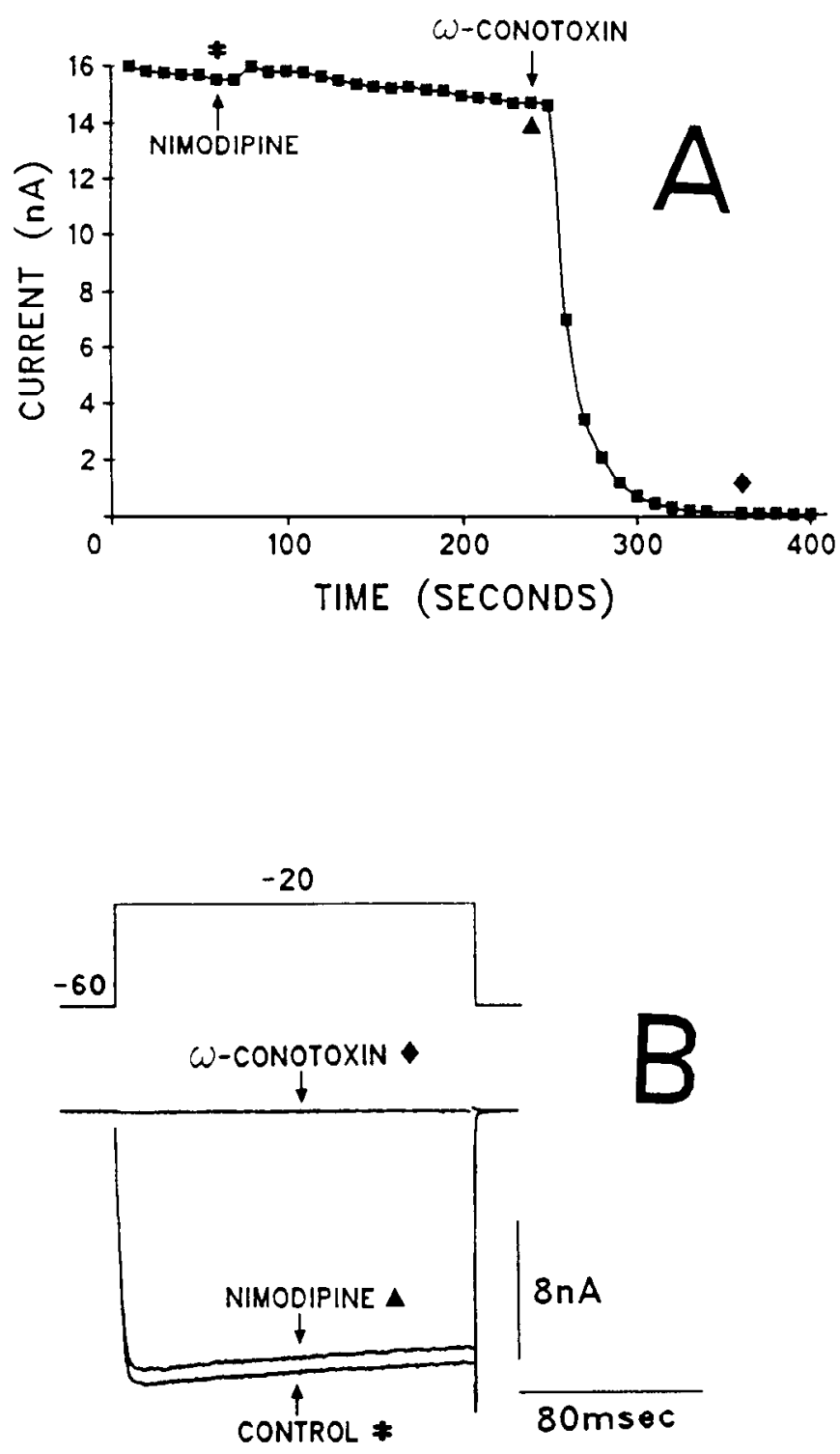

Figure 6. $\omega_{-C g T x}$ blocked all of the calcium current in most largediameter frog neurons. $A$, Plot of current versus time. The cell was depolarized to $-20 \mathrm{mV}$ from HP $-60 \mathrm{mV}$ every $10 \mathrm{sec}$. Note that superfusion with $2 \mu \mathrm{M}$ nimodipine did not decrease the amplitude of peak current. However, all of the peak current was blocked by $\omega-\mathrm{CgTx}$ which was added after the bath flow was stopped, near the neuron by pipette as a $100-\mu \mathrm{l}$ bolus at a concentration of $10 \mu \mathrm{M}$, achieving a final bath concentration of $0.9 \mu \mathrm{M} . B$, Superimposed current traces illustrating points along the plot of current versus time; control $\left({ }^{*}\right)$, after nimodipine $(\Delta)$, and after $\omega-C g T x(\Delta)$. External solution contained $110 \mathrm{mM}$ TEA$\mathrm{Cl}, 2 \mathrm{mM} \mathrm{BaCl}_{2}, 20 \mathrm{~mm}$ HEPES, $200 \mathrm{nM}$ TTX, pH 7.4. Internal solution contained $85 \mathrm{~mm} \mathrm{CsCl}, 5 \mathrm{~mm} \mathrm{Mg}-\mathrm{ATP}, 0.4 \mathrm{~mm} 2 \mathrm{Na}-\mathrm{GTP}, 10 \mathrm{~mm}$ EGTA, 20 mM HEPES, pH 7.4.

the graphs illustrate that at $\mathrm{HP}-80 \mathrm{mV}$, nimodipine was obscrved to produce an apparent increase in the inactivation rate over the course of the $200-\mathrm{msec}$ test depolarization. This effect of nimodipine was observed in 5 of 10 small-diameter rat neurons and in 5 of 6 small-diameter frog neurons and could be interpreted as nimodipine blocking more steady state current than initial peak current. On average, nimodipine blocked $12 \%$ of the peak current in small-diameter frog neurons and $23 \%$ of the peak current in small-diameter rat neurons (Table 1). Subsequent addition of $\omega$-CgTx blocked an average of $76 \%$ of the original peak current in the frog neurons and $48 \%$ of the original peak current in the rat neurons (Table 1). The effects $\omega$-CgTx and nimodipine were rapid in onset (20-60 sec) and the apparent peak effect occurred within 1-3 min after onset. In summary, increasing the holding potential from $-60 \mathrm{mV}$ to $-80 \mathrm{mV}$ decreased the percentage of peak current susceptible to blockade by nimodipine and increased the percentage of peak current susceptible to blockade by $\omega$-CgTx. The decrease in the effect of nimodipine at HP $-80 \mathrm{mV}$ was probably partly due to its voltage dependence which resulted in an only partial block of L-type channels. In addition, as more N-type calcium channels were recruited at $\mathrm{HP}-80 \mathrm{mV}$ versus $\mathrm{HP}-60 \mathrm{mV}$ (evidenced by the increase in the percentage of peak current blocked by $\omega-\mathrm{CgTx}$ ) it would be expected that the percentage of total peak current blocked by nimodipine would decrease.

When small-diameter frog neurons were held at $-60 \mathrm{mV}$, nearly $100 \%$ of the peak current was abolished by cumulative action of nimodipine and $\omega$-CgTx (Fig. 5A, Table 1). On the other hand, when the frog neurons were held at $-80 \mathrm{mV}$, an average of $13 \%$ of the peak current remained unblocked after treatment with both nimodipine and $\omega-\mathrm{CgTx}$ (Fig. $5 C$, Table 1). Therc was little evidence of low threshold current in three of the small-diameter frog neurons held at $-80 \mathrm{mV}$ as determined from I-V curves before drug addition. The $13 \%$ unblocked current in the frog neurons was unaffected by addition

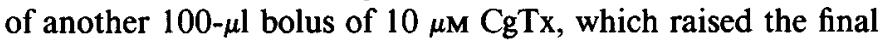
concentration of $\omega-\mathrm{CgTx}$ in the bath to $\approx 1.8 \mu \mathrm{M}(N=2)$. In rat neurons, an average of $15 \%$ of the peak current was unblocked by the cumulative action of nimodipine and $\omega-\mathrm{CgTx}$ at $\mathrm{HP}-60$ $\mathrm{mV}$ and $29 \%$ of the peak current remained unblocked after treatment with both antagonists at $\mathrm{HP}-80 \mathrm{mV}$ (Fig. $5 B, D$, Table 1). Based on $\mathrm{I}-\mathrm{V}$ data generated in small-diameter rat neurons, we could account for about $20 \%$ of the nimodipineand $\omega-\mathrm{CgTx}$-insensitive current by $\mathrm{T}$ currents at $\mathrm{HP}-80 \mathrm{mV}$ and none at $\mathrm{HP}-60 \mathrm{mV}$. In two of the rat neurons held at -80 $\mathrm{mV}$, and 1 rat neuron held at $-60 \mathrm{mV}$, the current that remained after treatment with nimodipine and $\omega-\mathrm{CgTx}$ was reduced by about half upon pipetting an additional $100 \mu \mathrm{l}$ of $50 \mu \mathrm{M} \omega-\mathrm{CgTx}$ into the bath, which increased the final concentration of $\omega-\mathrm{CgTx}$ to $\approx 5 \mu \mathrm{M}$. Thus, it appears that at HP $-60 \mathrm{mV}$ all of the peak current in small-diameter frog neurons could be accounted for by $\mathrm{N}$ and $\mathrm{L}$ channels. On the other hand, small-diameter rat neurons may possess a small proportion of $\omega-\mathrm{CgTx}$ - and DHPresistant calcium current at $\mathrm{HP}-60 \mathrm{mV}$ or rat L-type calcium channels may not be completely blocked by $2 \mu \mathrm{M}$ nimodipine at $\mathrm{HP}-60 \mathrm{mV}$.

The effects of nimodipine and $\omega-\mathrm{CgTx}$ were also studied on peak current in six large-diameter frog neurons that ranged in diameter $60-80 \mu \mathrm{m}$. In large-diameter frog neurons the peak current ranged 7-18 $\mathrm{nA}$ when evoked from $\mathrm{HP}-60 \mathrm{mV}$. Initial superfusion with $2 \mu \mathrm{M}$ nimodipine had no effect on peak current evoked from HP $-60 \mathrm{mV}$ in five of six of these neurons (illustrated in Fig. $6 A, B)$. However, in one large-diameter frog neuron, $2 \mu \mathrm{M}$ nimodipine blocked $19 \%$ of the peak current. The average blocking effect of nimodipine in all six large-diameter frog neurons was $3.6 \% \pm 3.36 \mathrm{SEM}$. The effect of nimodipine in the large-diameter frog neurons was significantly less than the $46 \% \pm 4.0$ SEM block previously observed in small-diameter frog neurons ( $p=0.0000036$, Student's $t$ test). In all six of the large-diameter frog neurons, subsequent addition of a $100-\mu \mathrm{l}$ bolus of $10 \mu \mathrm{M} \omega-\mathrm{CgTx}$ to the $1-\mathrm{ml}$ bath blocked $100 \%$ of the peak current remaining after treatment with nimodipine (Fig. 
$6 A, B)$. This data indicates a significant difference in the expression of L-type calcium channels between large-diameter and small-diameter frog sensory neuron somata.

As there is some continued controversy as to whether $\omega-\mathrm{CgTx}$ blocks L-type calcium currents (McCleskey et al., 1987; Aosaki and Kasai, 1989; Plummer et al., 1989), another series of experiments was performed specifically to address this question in small-diameter rat and frog neurons, which appear to express large numbers of this channel subtype. In one study, the blocking effect of a $100-\mu 1$ bolus of $10 \mu_{M} \omega-\mathrm{CgTx}$ was determined in small-diameter rat and frog neurons without prior nimodipine treatment, and compared to its effect in previous experiments, where the $\omega$-CgTx was added after blockade of $\mathrm{L}$ channels with nimodipine. The holding potential was $-60 \mathrm{mV}$ in these experiments. In the rat neurons, $\omega-\mathrm{CgTx}$ appeared to block more current on average when added without prior nimodipine treatment (average decrease $=44 \% \pm 7.7 \mathrm{SEM}, N=11$ ) than when it was added after superfusion with nimodipine (average decrease $=27 \% \pm 4.8 \mathrm{SEM}, N=5$ ). However, this effect was not significant ( $p=0.146$, Student's $t$-test). There appeared to be more variation in the effect of $\omega$-CgTx when added without prior nimodipine treatment (range, $14 \%-77 \%$ ) than when the $\omega$-CgTx was added after superfusion with nimodipine. The variation in the effect of $\omega-\mathrm{CgTx}$ when added without prior nimodipine treatment is illustrated in Figure 7, A and B. In five rat neurons where $\omega-\mathrm{CgTx}$ was added without prior nimodipine treatment (and the $\omega-\mathrm{CgTx}$ blockade was demonstrated to be irreversible after a 5 -min wash period), subsequent superfusion with $2 \mu \mathrm{M}$ nimodipine blocked an additional $35.6 \% \pm 15.9$ SEM of the original peak current (Fig. $7 A, B$ ). The effect of nimodipine added after $\omega$-CgTx was not significantly different from its effect when added before $\omega-\mathrm{CgTx}$ (average decrease $=58 \% \pm 6.3 \mathrm{SEM}$ ). However, there appeared to be more variation in the effects of nimodipine when added after $\omega$-CgTx than when added before $\omega$-CgTx (Fig. 7A,B).

In small-diameter frog neurons held at $-60 \mathrm{mV}, \omega$-CgTx also appeared to block more current when added without prior nimodipine treatment (average decrease $=68 \% \pm 9.5 \mathrm{SEM}, N=$ 7) than when added after superfusion with nimodipine (average decrease $=52 \% \pm 4.3 \mathrm{SEM}, N=7$ ); however, this effect was also not significant ( $p=0.134$, Student's $t$ test). Similar to the previous observation in rat neurons, there appeared to be more variation in the effect of $\omega-\mathrm{CgTx}$ when added without prior nimodipine treatment than when added after superfusion with nimodipine. Nevertheless, this data does not demonstrate a significant overlap in the current blocked by $\omega$-CgTx and nimodipine. In addition, the DHP agonist (-)Bay K 8644 was demonstrated to produce a marked increase in peak current in two of three small-diameter rat neurons when added after treatment with $\omega$-CgTx (Fig. 8A,B). The data indicates that while $\omega$-CgTx may have small effect on L-type calcium channels, it is not a potent blocker of this channel subtype.

To explore further the possibility of $\mathbf{L}$ channel blockade by $\omega$-CgTx, wc studicd the cffcets of $\omega$-CgTx on the large slowly inactivating tail current induced by Bay K 8644. Seven smalldiameter rat neurons were exposed to $2 \mu \mathrm{M}( \pm)$ Bay K 8644 superfused through the bath $(N=3)$ or a $100-\mu$ l bolus of 200 $\mathrm{nM}(N=3)$ or $20 \mu \mathrm{M}(N=1)(-)$ Bay K 8644 . Note in Figure $9 A$ that in the presence of Bay K 8644, peak current "ran down" faster than control peak current. After "rundown," which followed the Bay K 8644-induced increase in peak current, had reached a steady state, a $100-\mu$ l bolus of $10 \mu \mathrm{M} \omega-\mathrm{CgTx}$ was
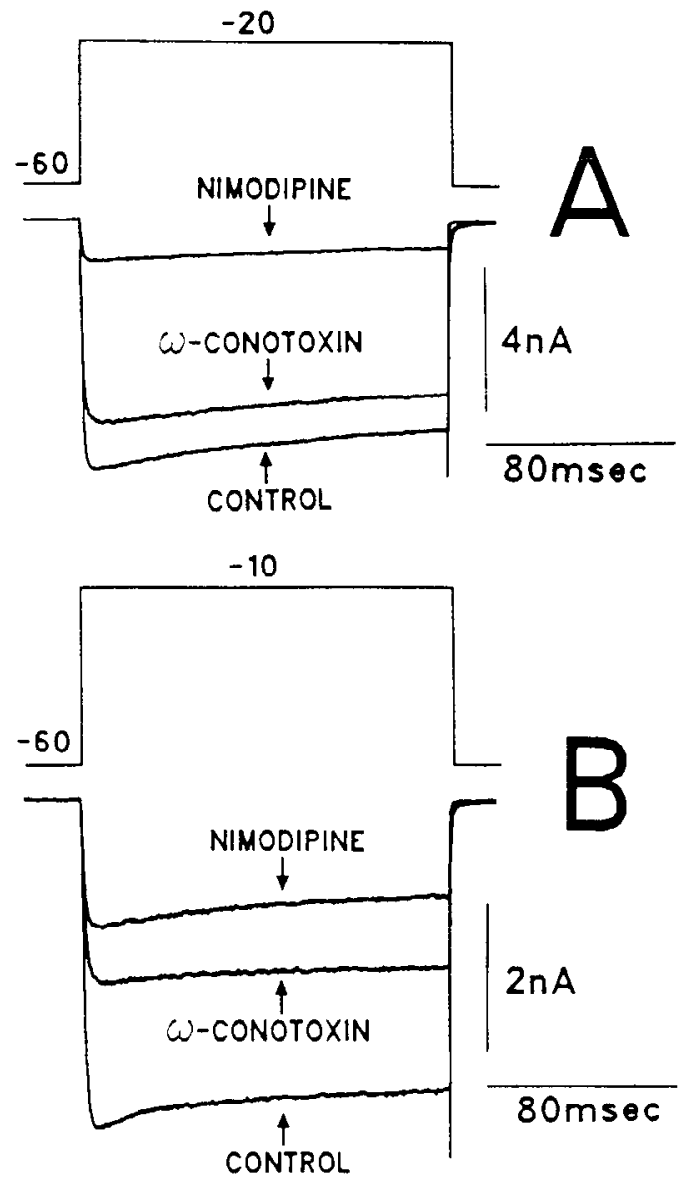

Figure 7. $\omega$-CgTx treatment alone blocked various amounts of peak current but left nimodipine sensitive calcium current unblocked in small diameter rat DRG neurons. Addition of a $100-\mu \mathrm{l}$ bolus of $10 \mu \mathrm{M}$ $\omega$-CgTx to the $1-\mathrm{ml}$ bath (flow stopped) blocked $14 \%$ of peak current in experiment $A$, and $42 \%$ of peak current in experiment $B$. Subsequent superfusion with $2 \mu \mathrm{M}$ nimodipine blocked $68 \%$ of the current remaining after $\omega-\mathrm{CgTx}$ treatment in experiment $A$ and $15 \%$ of the remaining current in experiment $B$. The holding potential was $-60 \mathrm{mV}$ in $A$ and $B$. Solutions as in Figure 2.

added to the $1-\mathrm{ml}$ hath. Surprisingly, in four of seven neurons, $\omega$-CgTx produced a transient increase in peak current (Fig. 9A) that was accompanied by a transient increase in the amplitude and duration of the tail current (Fig. 9B). In one of seven neurons, $\omega-\mathrm{CgTx}$ produced a transient increase in the Bay $\mathrm{K}$ 8644induced tail current that was not accompanied by an increase in peak current. These transient increases returned to control levels within 1-2 min (Fig. 9A-C). We did not observe a block of the Bay K 8644-induced tail current by $\omega$-CgTx following the transient increase (Fig. 9C). Also, we observed less than the expected blocking effect of $\omega$-CgTx on peak current based on the effect of $\omega$-CgTx in previous experiments (Fig. 9C). The average decrease induced by $\omega-\mathrm{CgTx}$ in the seven rat neurons pretreated with Bay K 8644 was $5.4 \% \pm 2.71$ SEM, compared to a dccrease of $26.5 \% \pm 4.8 \mathrm{SEM}$ in small-diameter rat neurons pretreated with nimodipine or a decrease of $44.2 \pm 7.7$ SEM in small-diameter rat neurons where $\omega-\mathrm{Cg} \mathrm{Tx}$ was added prior to other drug treatment. Thus, while the data indicates that $\omega$-CgTx is not a potent blocker of $L$ channels it appears that Bay K 8644 may affect the interaction of $\omega$-CgTx with L- and $\mathrm{N}$-type channels.

The reversibility of the block induced by treatment with a $100-\mu 1$ bolus of $10 \mu \mathrm{M} \omega-\mathrm{CgTx}$ was studied in several rat and 

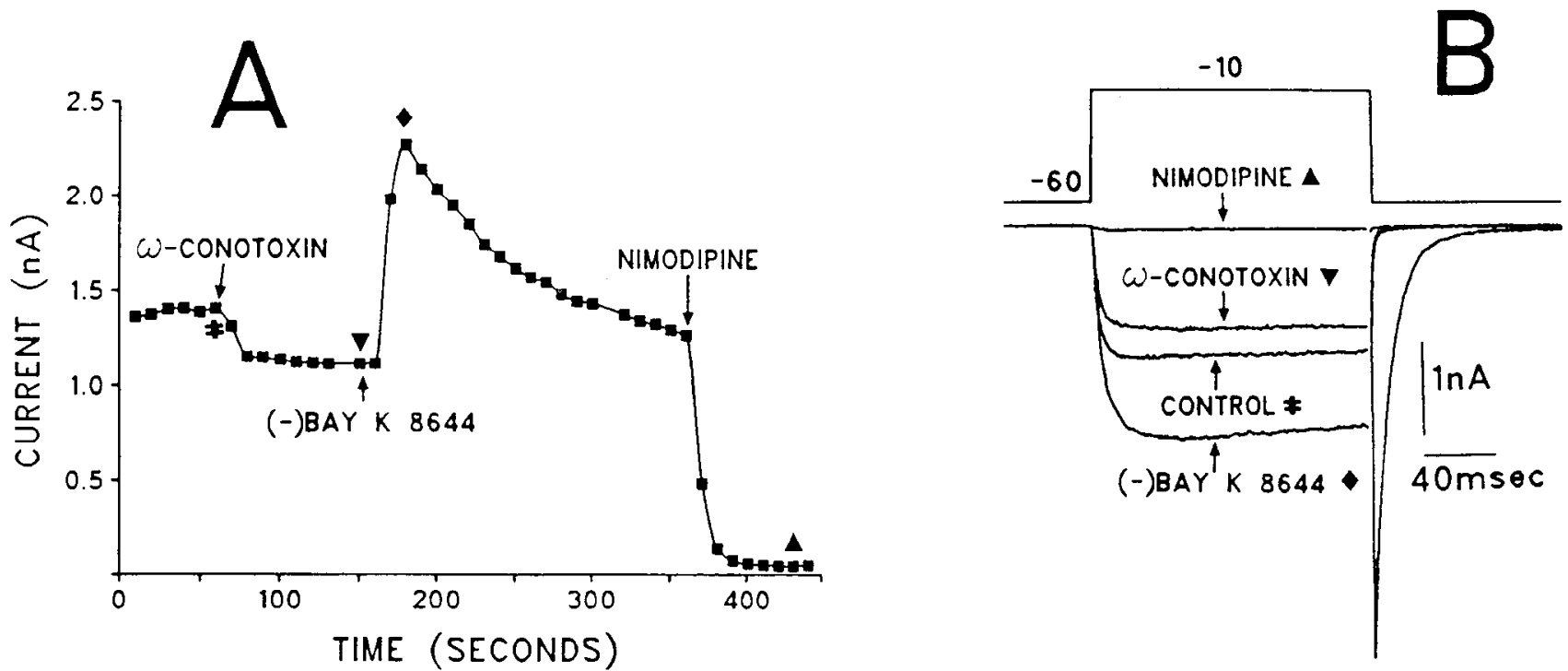

Figure 8. Bay K 8644 increased the amplitude of peak current after treatment with $\omega$-CgTx in a small-diameter rat DRG neuron. A, Plot of current versus time. The cell was depolarized to $-10 \mathrm{mV}$ every $10 \mathrm{sec}$ from a holding potential of $-60 \mathrm{mV}$. Bath flow was stopped and a $100-\mu \mathrm{l}$ bolus of $10 \mu \mathrm{M} \omega$-CgTx was pipetted into the $1-\mathrm{ml}$ bath near the neuron, achieving a final concentration of $0.9 \mu \mathrm{M}$, which blocked a small portion of the peak current. Subsequently, a 100- $\mu$ l bolus of $200 \mathrm{nM}(-)$ Bay K 8644 was pipetted into the bath near the neuron, achieving a final concentration of $18 \mathrm{nM}$, which increased peak current dramatically. In the presence of Bay $\mathrm{K} 8644$, the peak current decreased over time faster than under control conditions. After this change in current versus time had reached a steady state, a $100-\mu 1$ bolus of $20 \mu \mathrm{M}$ nimodipine was pipetted into the bath, achieving a final concentration of $1.8 \mu \mathrm{M}$, which blocked most of the peak current. $B$, Superimposed current traces illustrating points along the plot of current versus time; control $\left({ }^{*}\right)$, after $\omega-C g T x(\nabla)$, after Bay $K 8644(\$)$, after nimodipine (A). The holding potential in $A$ and $B$ was $-60 \mathrm{mV}$. Solutions as in Figure 2.

frog neurons held at $-60 \mathrm{mV}$. After treatment with toxin, the neurons were washed with a toxin-free solution. In seven of eight small-diameter rat neurons treated with $\omega$-CgTx, the effects of $\omega-\mathrm{CgTx}$ were not reversed over the course of a 5 -min wash period with $\mathrm{Ba}^{2+}$-TEA buffer (average change $=0.04 \% \pm 1.8$ SEM, compared with control peak current). In the remaining rat neuron, a noticeable $8.3 \%$ reversal of the $\omega-\mathrm{CgTx}$ induced block was observed, which plateaued within $5 \mathrm{~min}$. No reversal of the effects of $\omega$-CgTx was observed in four small-diameter rat neurons that were first superfused with nimodipine and washed with control solution containing nimodipine. In smalldiameter frog neurons, a reversal of $\omega$-CgTx induced block was observed in three of four neurons where $\omega-\mathrm{CgTx}$ was tested alone and in one of two neurons where $\omega-\mathrm{CgTx}$ was added after treatment with nimodipine and washed with control solution containing nimodipine. The magnitude of reversal of $\omega$-CgTx block in frog neurons ranged from $6 \%$ to $25 \%$ of the control whole cell current. Also, reversal of $\omega$-CgTx block was observed in each of three large-diameter frog neurons where a washout was performed as illustrated in Figure $10 \mathrm{~A}$ and $\mathrm{B}$. We never observed a diminution of the effects of $\omega-\mathrm{CgTx}$ as a result of diffusion of the original concentrated bolus away from the neuron under study. The observation that $\omega-\mathrm{CgTx}$ is reversible in some neurons but not others may indicate $\mathrm{N}$-type calcium channel subtypes.

\section{Discussion}

This study clearly demonstrates the presence of DHP agonistand antagonist-sensitive calcium current in small-diameter rat and frog DRG neuron somata, which provides strong evidence for a large component of L-type calcium channels in these neurons (Fox et al., 1987a,b). The lack of effect of $2 \mu \mathrm{M}$ nimodipine in some neurons (large-diameter frog neurons) argues against a nonspecific action of nimodipine. Similar concentrations of DHP antagonists have been shown to have little effect on calcium currents carried through N-type channels (Fox et al., 1987b; Hirning et al., 1988; Jones and Jacobs, 1990). While there have been reports of DHP antagonists blocking T-type calcium currents, there was little $\mathrm{T}$ current available at $\mathrm{HP}-80 \mathrm{mV}$ and none at $\mathrm{HP}-60 \mathrm{mV}$ in the small-diameter rat and frog neurons. Thus, the current blocked by nimodipine in our study appears to be L-type. Additional evidence for the presence of L-type calcium channels in the small-diameter rat neurons is the dramatic increase in current observed after treatment with the DHP agonist Bay K 8644. These results are similar to those obtained in hippocampal CA1 and CA3 neurons, which also have large components of L-type calcium current (Sah et al., 1989; Mogul and Fox, 1990). The small-diameter rat neuron somata used for these studies were, on average, within the range reported for the somata of C-and A $\delta$-type DRG neurons but were smaller than the diameter reported for most $A \alpha$ - and $A \beta$-type DRG neurons in rat (Harper and Lawson, 1985a). Unfortunately we were unable to find data relating direct measurements of somata diameter with conduction velocity for frog DRG neurons. However, measurements of input resistance, which can be a reflection of cell membrane surface area, have demonstrated that frog C-type DRG neurons had higher values (67 M $2 \pm 8 \mathrm{SEM})$ than frog A-type DRG neurons (32 M $2 \pm 3$ SEM; Holz et al., 1985). This could be interpreted as A-type neuron somata being larger than C-type neuron somata in frog DRG. We observed that nimodipine had no effect on the majority of large-diameter frog neuron somata studied, which indicates that L channels did not contribute much to peak current in these cells. These DRG neuron somata were the largest present after the isolation procedure and were possibly somata of fast conducting A-type neurons. In support of this idea, a previous study reported that the TEA-induced calcium-dependent plateau of action potentials recorded from fast conducting A-type frog DRG neuron somata 
(as defined by conduction velocity along the peripheral axon) was not sensitive to Bay K 8644 but was completely blocked by $\omega$-CgTx (Scroggs and Anderson, 1989). The different pharmacological profile of peak current recorded from the smallversus large-diameter frog neurons leads us to hypothesize that there is variation in the expression of different calcium channel subtypes in DRG neurons which transmit different sensory modalities. This can be compared to the variation in the expression of calcium channel subtypes in different types of neurons. Peak calcium current in sympathetic, dorsal raphe, and Purkinje neurons were relatively insensitive to DHP agonists and/or antagonists (Jones and Jacobs, 1990; Plummer et al., 1989; Sah et al., 1989; Pennington, personal communication), while a significant portion of peak current in hippocampal neurons was blocked by DHP antagonists (Sah et al., 1989; Mogul and Fox, 1990).

A larger proportion of the peak current was sensitive to nimodipine when the holding potential was $-60 \mathrm{mV}$ as compared to a holding potential of $-80 \mathrm{mV}$. The reduction in the inhibition produced by nimodipine at $\mathrm{HP}-80 \mathrm{mV}$ could be partly caused by a greater proportion of the peak current evoked from $\mathrm{HP}-80 \mathrm{mV}$ being composed of DHP-insensitive N-type channels, when compared to HP $-60 \mathrm{mV}$ (Fox et al., 1987a,b). Alternatively, it is well known that the efficacy of DHP binding and current suppression increases at more depolarized holding potentials (Bean, 1984; Sanguinetti and Kass, 1984; Cohen and McCarthy, 1987; Jones and Jacobs, 1990). It is probable that the voltage dependence of nimodipine caused some of the decrease in block observed at $\mathrm{HP}-80 \mathrm{mV}$. In the small-diameter rat neurons, changing the holding potential from $-60 \mathrm{mV}$ to $-80 \mathrm{mV}$ increased the amplitude of the peak current by an average of $79 \%$. Even if all of this increase was due to recruitment of $\mathrm{N}$-type channels the $23 \%$ block produced by nimodipine at $\mathrm{HP}-80 \mathrm{mV}$ is less than the $32 \%$ we expected based on the nimodipine block observed at $\mathrm{HP}-60 \mathrm{mV}$. (The expected block at $\mathrm{HP}-80 \mathrm{mV}$ was calculated by dividing the $58 \%$ observed block at $\mathrm{HP}-60 \mathrm{mV}$ by 1.79 , assuming that all $\mathrm{L}$ channels were reprimcd at $\mathrm{HP}-60 \mathrm{mV}$.) This same argument holds for the small-diameter frog neurons, where changing the holding potential from $-60 \mathrm{mV}$ to $-80 \mathrm{mV}$ produces a similar magnitude of increase in peak current as observed in the rat neurons. The expected block by nimodipine at $\mathrm{HP}-80 \mathrm{mV}$ should have been $27 \%$ versus $12 \%$ which we actually observed (based on the observed $46 \%$ block at $\mathrm{HP}-60 \mathrm{mV} \div 1.7$ ). Nimodipine produced an increase in the rate of inactivation of peak current over the duration of 200 -msec depolarizations in many of the small-diameter rat and frog neurons. This could be explained by changes (during the duration of the depolarization) in the $\mathrm{L}$ channel gating to an open and/or voltage-inactivated state, which have a higher affinity for DHP antagonists (Bean, 1984; Sanguinetti and Kass, 1984; Cohen and McCarthy, 1987). A similar increase in inactivation rate in the presence of nimodipine has been observed in other cell types such as rat anterior pituitary cells (Cohen and McCarthy, 1987). The effect of HP on the block of peak current produced by $\omega$-CgTx was exactly the opposite of that observed with nimodipine, that is, $\omega-\mathrm{CgTx}$ blocked more current at $\mathrm{HP}-80 \mathrm{mV}$ than at $\mathrm{HP}-60 \mathrm{mV}$ in both the rat and frog small-diameter neurons. As more negative HPs primarily reprime $\mathrm{N}$-type as opposed to L-type calcium channels, it is expected that there would be a larger proportion of $\omega$-CgTx-sensitive $\mathrm{N}$-type channels present at $\mathrm{HP}-80 \mathrm{mV}$ when compared to $\mathrm{HP}-60 \mathrm{mV}$.
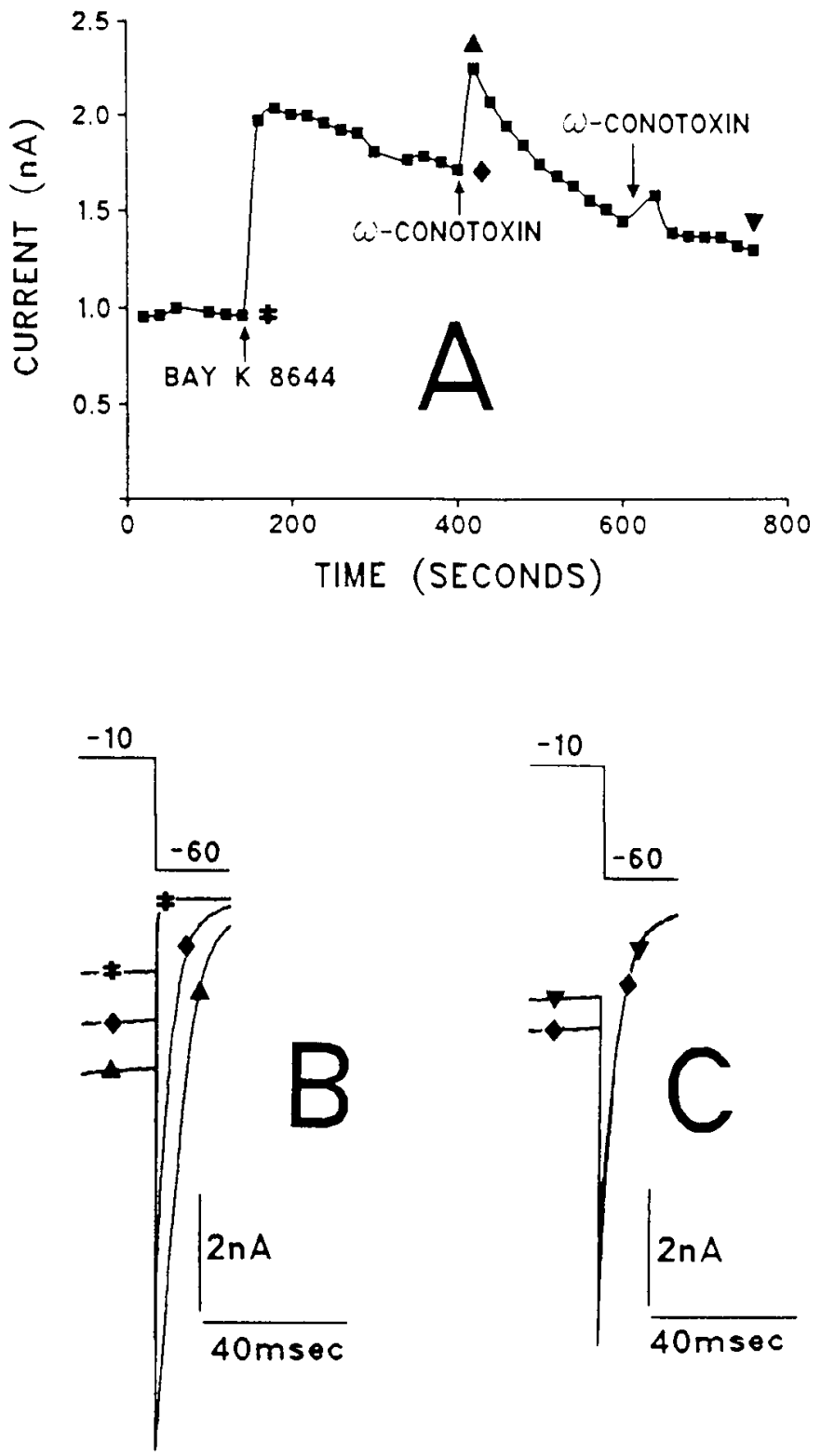

Figure 9. Anomalous effects of $\omega-\mathrm{CgTx}$ after Bay $\mathrm{K} 8644$ of a smalldiameter rat DRG neuron. $A$, Plot of peak current versus time. Cell was depolarized to $-10 \mathrm{mV}$ from HP $-60 \mathrm{mV}$ every $20 \mathrm{sec}$. Superfusion with $2 \mu_{\mathrm{M}}( \pm)$ Bay K 8644 (immediately after left arrow) doubled peak current, after which peak current decreased over time more rapidly than under control conditions. Bath flow was stopped and a $100-\mu 1$ bolus of $10 \mu \mathrm{M} \omega-\mathrm{CgTx}$ was pipetted into the $1-\mathrm{ml}$ bath near the neuron (immediately after middle arrow), achieving a final concentration of 0.9 $\mu \mathrm{M}$, which produced a transient increase in peak current. A second application of $\omega-\mathrm{CgTx}$ (immediately after right arrow) produced a smaller transient increase in peak current. $\omega$-CgTx did not appear to produce a significant block of peak current. $B-C$, Overlay of the last $20 \mathrm{msec}$ of whole cell current evoked by a $200-\mathrm{msec}$ step from $\mathrm{HP}-60 \mathrm{mV}$ to a test potential of $-10 \mathrm{mV}$ and tail currents (evoked upon returning to the HP). These sweeps were taken from the experiment depicted in part $A$. Part B, control $(*)$, after addition of Bay $\mathrm{K} 8644$, immediately before addition of $\omega-C g T x(\bullet)$, immediately after addition of $\omega-C g T x(\Delta)$, and part $C$, seventh sweep after the second addition of $\omega$-CgTx, superimposed on the sweep taken immediately before the first addition of $\omega-\mathrm{CgTx}$. Note that $\omega-\mathrm{CgTx}$ produced an increase in the duration and amplitude of the Bay K 8644-induced tail current illustrated in part $B$, but did not result in a blockade of this tail current as illustrated in part C. Solutions as in Figure 2. 

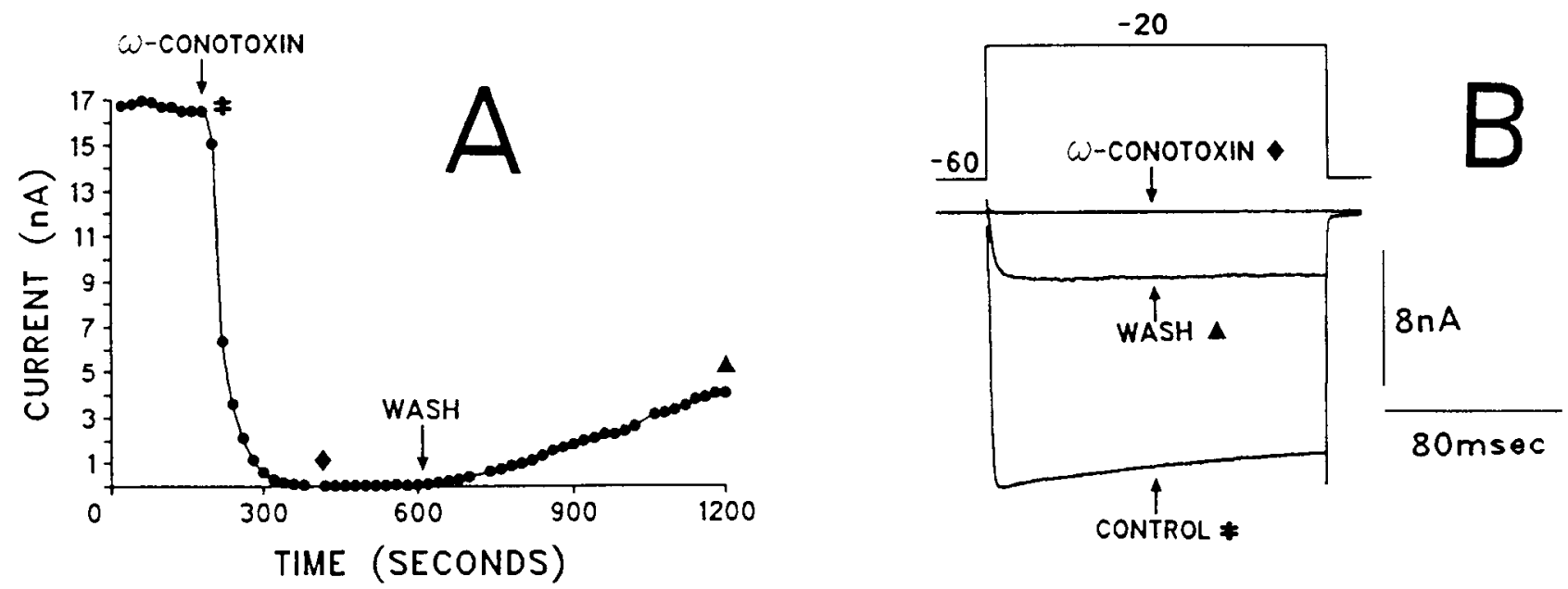

Figure 10. Washout of the $\omega$-CgTx blockade in a large-diameter frog neuron. A, Current versus time plot. Cell was depolarized every 20 sec to $-20 \mathrm{mV}$ from HP $-60 \mathrm{mV}$. After bath flow was halted, addition of a $100 \mu$ l bolus of $10 \mu \mathrm{M} \omega-\mathrm{CgTx}$ near the neuron, achieving a final concentration of $0.9 \mu \mathrm{M}$, blocked $100 \%$ of the peak current. Prior superfusion with $2 \mu \mathrm{M}$ nimodipine had demonstrated that this frog neuron did not express nimodipine-sensitive calcium current. Subsequent wash of the bath with $\omega$-CgTx-free control buffer resulted in the gradual recovery of current. $B$, Current traces illustrating points along the plot of current versus time; control $(*)$, after $\omega-C g T x(\$)$, after 10 min of washout (A). HP was -60 $\mathrm{mV}$ in $A$ and $B$. Solutions as in Figure 6.

Whether $\omega$-CgTx is capable of blocking $L$ channels is controversial, as there are reports of no blockade, reversible blockade, and irreversible blockade (Fox et al., 1987a; Kasai et al., 1987; McCleskey et al., 1987; Holz et al., 1988; Aosaki and Kasai, 1989; Plummer et al., 1989). Although most of our data indicate that $\omega$-CgTx does not potently block L channels, some of the data suggest that there may be some overlap in the current affected by DHPs (L channels) and in that affected by $\omega$-CgTx. In small-diameter rat and frog neurons, there appeared to be a greater average block and more variation in the blocking effects of $\omega-\mathrm{CgTx}$ when added without prior nimodipine treatment when compared to adding $\omega$ - $\mathrm{CgTx}$ after prior nimodipine treatment. This may indicate that $\omega-\mathrm{CgTx}$ has some weak $\mathrm{L}$ channel blocking activity or that it blocks a subgroup of $\mathrm{L}$ channels that varies in prevalence from cell to cell. Also, the interaction of $\omega$-CgTx and Bay K 8644 discussed below may be seen as evidence for some kind of interaction of $\omega-\mathrm{CgTx}$ with $\mathrm{L}$ channels.

Nonetheless, when all the data was analyzed quantitatively, we observed that there was not a statistically significant differences in the percentage of peak current blocked by $\omega$-CgTx when it was tested before or after prior treatment with nimodipine in small-diameter rat and frog neurons. In addition, after treating the small-diameter rat neurons with $\omega$-CgTx, a large response to either nimodipine and/or Bay K 8644 could be elicited, indicating the presence of unblocked $L$ channels. An apparent lack of overlap of nimodipine and $\omega$-CgTx was also observed in the large-diameter frog neurons, where $\omega$-CgTx blocked all calcium current in several neurons while nimodipine had no effect. These observations suggest that $\omega$-CgTx is not a potent blocker of all L channels.

In rat sympathetic neurons, $\omega$-CgTx did not affect the large $L$ channel tail currents induced by treatment with the DHP agonist (+) 202-971 (Plummer et al., 1989). We observed similar effects: $\omega-\mathrm{CgTx}$ failed to block Bay K 8644-enhanced tail currents. However, we unexpectedly observed that administration of a $100-\mu \mathrm{l}$ bolus of $10 \mu \mathrm{M} \omega-\mathrm{CgTx}$ produced a transient increase in the tail current and peak current in several of the small-diameter rat neurons pretreated with Bay K 8644. This may indicate some type of positive cooperativity between the binding sites for $\omega-\mathrm{CgTx}$ and Bay K 8644. Another unexpected finding was that the presence of Bay K 8644 appeared to antagonize the blocking effect of $\omega$-CgTx on peak current. This latter observation raises the possibility that Bay K 8644 blocked or somehow protected calcium channels normally sensitive to $\omega$-CgTx. The observation that "rundown" in the presence of Bay K 8644 was faster than observed under control conditions may represent the block of $\mathrm{N}$ channels by Bay $\mathrm{K} 8644$, leaving fewer $\mathrm{N}$ channels to be blocked by a subsequent addition of $\omega-\mathrm{CgTx}$. Evidence of DHP agonists producing a block of $\mathrm{N}$ currents has previously been observed in frog sympathetic neurons (Jones and Jacobs, 1990). In the small- and large-diameter frog neurons held at $-60 \mathrm{mV}$, we observed a complete blockade of peak current after treatment with nimodipine and $\omega-\mathrm{CgTx}$ in the presence of $2 \mathrm{~mm}$ extracellular $\mathrm{Ba}^{2+}$. This obscrvation is contrary to binding studies which demonstrate that divalent cations prevent $\omega-\mathrm{CgTx}$ from binding to a significant proportion of high affinity sites in rat nervous tissue (Abe et al., 1986; Cruz and Olivera, 1986). In the Abe et al. (1986) study $50 \%$ of $\omega-\mathrm{CgTx}$ binding to rat brain membranes was inhibited by $1 \mathrm{~mm}$ $\mathrm{Ba}^{2+}$. Our studies in the small- and large-diameter frog neurons suggest that calcium current inhibition by $\omega$-CgTx was not greatly affected by $2 \mathrm{mM} \mathrm{Ba}^{2+}$. However, in the small-diameter rat neurons held at $-60 \mathrm{mV}$ some current remained unblocked by treatment with nimodipine and $\omega-\mathrm{Cg} \mathrm{Tx}$. This may indicate that a subtype of calcium channel exists in rat in which $\omega$-CgTx binding is more sensitive to the presence of divalent ions. This idea is supported by the observation that a higher concentration of $\omega$-CgTx resulted in additional current blockade in the smalldiameter rat neurons. Alternative mechanisms might include $\mathrm{L}$ channels in rat that arc less sensitive to nimodipine than those in frog or the presence of a DHP- and $\omega-\mathrm{Cg} T x$-insensitive calcium channel in rat but not frog. Recently a DHP- and $\omega$-CgTxinsensitive " $P$ " calcium channel has been described in rat cerebellar Purkinje neurons (Llinás et al., 1989; Sah et al., 1989). In any case, the amount of DHP- and $\omega$-CgTx-insensitive currents in the small-diameter rat neurons was quite small. 
Partial reversal of $\omega$-CgTx-induced block was frequently observed in the large- and small-diameter frog neurons, but infrequently in the small-diameter rat neurons. Previous studies have suggested that $\omega-\mathrm{CgTx}$ may have reversible effects on $\mathrm{N}$ or $\mathrm{L}$ channels. Plummer et al. (1989) observed reversible effects in rat sympathetic neurons that could be most easily explained as $\omega$-CgTx washing off of $\mathrm{N}$-type channels, as only a small percentage of the total current was L-type. On the other hand, Aosaki and Kasai (1989) observed partial reversal of $\omega-\mathrm{CgTx}$ block in cultured chick sensory neurons. The current that they recovered was subsequently blocked by a DHP antagonist, and thus appeared to be L-type. The reversibility of $\omega-\mathrm{CgTx}$ in our study could best be explained as resulting from a reversible block of a subtype of $\mathrm{N}$ channel, based on the observation that reversal of $\omega$-CgTx was observed in the large-diameter frog neurons which expressed few L-type calcium channels.

It appears that a substantial portion of peak calcium current in the small-diameter frog and rat sensory neurons was conducted through both $\mathrm{L}$ channels and $\mathrm{N}$ channels, at potentials near the resting potential of these neurons, while calcium currents in large-diameter frog neurons were conducted mostly through $\mathrm{N}$ channels. The pharmacology of the calcium currents found in the small-diameter frog and rat sensory neurons was quite similar. However, the presence of calcium current which is unblocked by the combination of nimodipine and $\omega-\mathrm{CgTx}$ in the small-diameter rat neurons held at $-60 \mathrm{mV}$ may indicate an additional subtype(s) of calcium channels present in rat DRG neurons but not in frog DRG neurons. Also, the more frequent reversibility of $\omega$-CgTx block in the frog neurons versus the rat neurons suggests that different subtypes of $\mathrm{N}$ - or L-type calcium channels may exist.

\section{References}

Abe T, Koyano K, Saisu H, Nishiuchi Y, Sakakibara S (1986) Binding of $\omega$-conotoxin to receptor sites associated with the voltage-sensitive calcium channel. Neurosci Lett 71:203-208.

Akaike N, Kostyuk PG, \& Osipchuk IV (1989) Dihydropyridine sensitive low threshold calcium channels in isolated rat hypothalamic neurones. J Physiol (Lond) 412:181-195.

Aosaki T, Kasai H (1989) Characterization of two kinds of highvoltage-activated $\mathrm{Ca}$-channel currents in chick sensory neurons: differential sensitivity to dihydropyridines and $\omega$-conotoxin GVIA. Pfluegers Arch 414:150-156.

Bean BP (1984) Nitrendipine block of cardiac calcium channels: highaffinity binding to the inactivated state. Proc Natl Acad Sci USA 81: 6388-6392.

Boland LM, Dingledine R (1990) Multiple components of both transient and sustained barium currents in a rat dorsal root ganglion cell line. J Physiol (Lond) 420:223-245.

Carbone E, Lux HD (1984a) A low voltage-activated calcium conductance in embryonic chick sensory neurons. Biophys J 46:413-418.

Carbone E, Lux HD (1984b) A low voltage-activated, fully inactivating $\mathrm{Ca}$ channel in vertebrate sensory neurons. Nature 310:501502.

Cohen CJ, McCarthy RT (1987) Nimodipine block of calcium channels in rat anterior pituitary cells. J Physiol 387:195-225.

Cruz LJ, Olivera BM (1986) Calcium channel antagonists: $\omega$-conotoxin defines a new high affinity site. J Biol Chem 14:6230-6233.

Fedulova SA, Kostyuk PK, Veselovsky NS (1985) Two types of calcium channels in the somatic membrane of new-born rat dorsal root ganglion neurones. J Physiol (Lond) 359:431-446.

Fox AP, Nowycky MC, Tsien RW (1987a) Kinetic and pharmacological properties distinguish three types of calcium currents in chick sensory neurons. J Physiol (Lond) 394:149-172.

Fox AP, Nowycky MC, Tsien RW (1987b) Single channel recordings of three types of calcium channels in chick sensory neurons. J Physiol (Lond) 394:173-200.
Harper AA, Lawson SN (1985a) Conduction velocity is related to morphological cell type in rat dorsal root ganglion neurones. J Physiol (Lond) 359:31-46.

Harper AA, I awson SN (1985b) Electrical properties of rat dorsal root ganglion neurones with different peripheral nerve conduction velocities. J Physiol (Lond) 359:47-63.

Hess P, Lansman JB, Tsien RW (1984) Different modes of Ca channel gating behavior favored by dihydropyridine $\mathrm{Ca}$ agonists and antagonists. Nature 31 1:538-544.

Hirning LD, Fox AP, McCleskey EW, Miller RJ, Olivera BM, Thayer SA, Tsien RW (1988) Dominant role of $\mathrm{N}$-type $\mathrm{Ca}^{2+}$ channels in evoked release of norepinephrine from sympathetic neurons. Science 239:57-61.

Holz GG IV, Shefner SA, Anderson EG (1985) Serotonin depolarizes type $A$ and $C$ primary afferents: an intracellular study in bullfrog dorsal root ganglion. Brain Res 327:71-79.

Holz GG IV, Shefner SA, Anderson EG (1986) Serotonin decreases the duration of action potentials recorded from tetraethylammoniumtreated bullfrog dorsal root ganglion cells. J Neurosci 6:620-626.

Holz GG IV, Dunlap K, Kream RM (1988) Characterization of the electrically evoked release of substance $P$ from dorsal root ganglion neurons: methods and dihydropyridine sensitivity. J Neurosci 8:463471.

Jones SW, Jacobs LS (1990) Dihydropyridine actions on calcium currents of frog sympathetic neurons. J Neurosci 10:2261-2267.

Kasai H, Aosaki T, Fukuda J (1987) Presynaptic Ca-antagonist $\omega$-conotoxin irreversibly blocks $\mathrm{N}$-type $\mathrm{Ca}$-channels in chick sensory neurons. Neurosci Res 4:228-235.

Kokubun S, Reuter H (1984) Dihydropyridine derivatives prolong the open state of $\mathrm{Ca}$ channels in cultured cardiac cells. Proc Natl Acad Sci USA 81:4824-4827.

Kunze DL, Ritchie AK (1990) The DHP sensitive calcium channel in $\mathrm{GH}^{3}$ cells exhibits multiple conductance levels. Biophys J 57:396a, Abs W-PM-C9.

Lee KH, Chung K, Chung JM, Coggeshall RE (1986) Correlation of cell body size, axon size, and signal conduction velocity for individually labeled dorsal root ganglion cells in the cat. J Comp Neurol 243: 335-346.

Llinás R, Yarom Y (1981) Electrophysiology of mammalian inferior olivary neurones in vitro: different types of voltage-dependent ionic conductances. J Physiol (Lond) 315:549-567.

Llinás, RR, Sugimori M, Cherksey B (1989) Voltage-dependent calcium conductances in mammalian neurons: the $\mathrm{P}$ channel. Ann NY Acad Sci 560:103-111.

Martin JH (1985) Sensory systems of the brain: sensation and perception. In: Principles of neural science (Kandel ER, Schwartz JH, eds), pp 285-383. New York: Elsevier.

McCleskey EW, Fox AP, Feldman D, Cruz LJ, Olivera BM, Tsien RW, Yoshikami D (1987) $\omega$-Conotoxin direct and persistent blockade of specific types of calcium channels in neurons but not muscle. Proc Natl Acad Sci USA 84:4327-4331.

Mogul DJ, Fox AP (1990) Characterization of Ca channels in acutely isolated hippocampal CA3 pyramidal neurons: possible evidence for four different types of Ca Channels. J Physiol., in press.

Morita K, Katayama Y (1987) 5-hydroxytryptamine effects on the somata of bullfrog primary afferent neurons. Neuroscience 21:10071018.

Nowycky MC, Fox AP, Tsien RW (1985a) Long-opening mode of gating of neuronal calcium channels and its promotion by the dihydropyridine calcium agonist Bay K 8644. Proc Natl Acad Sci USA 82:2178-2182.

Nowycky MC, Fox AP, Tsien RW (1985b) Three types of calcium channel with different calcium agonist sensitivity. Nature 316:440443.

Perney TM, Hirning LD, Miller RJ (1986) Multiple calcium channels mediate neurotransmitter release from peripheral neurones. Proc Natl Acad Sci USA 83:6656-6659.

Plummer MR, Logothetis DE, Hess P (1989) Elementary properties and pharmacological sensitivities of calcium channels in mammalian peripheral neurons. Neuron 2:1453-1463.

Sah, DWY, Regan L, Bean BP (1989) Calcium channels in rat neurons: high-threshold channels that are resistant to both $\omega$-conotoxin and dihydropyridine blockers. Soc Neurosci 15:823, Abs. 332.6

Sanguinetti MC., Kass RS (1984) Voltage-dependent block of calcium channel current in the calf cardiac Purkinje fiber by dihydropyridine derivatives. Circ Res 55:284-297. 
Scroggs RS, Anderson EG (1989) Serotonin modulates a calciumdependent plateau of action potentials recorded from bull frog A-type sensory neurons which is $\omega$-conotoxin GVIA-sensitive, but dihydropyridine-insensitive. Brain Res 485:391-395.

Tang CN, Presser F, Morad M (1988) Amiloride selectively blocks the low threshold (T) calcium channel current. Science 240:213-215.
Tsien RW, Madison DV, Lipscombe D, Fox AP (1989) Multiple types of neuronal calcium channels and their selective modulation. Trends Neurosci 11:431-437.

Yoshida S, Matsuda Y (1979) Studies on sensory neurons of the mouse with intracellular recording and horseradish peroxidase-injection techniques. J Neurophysiol 42:1134-1145. 